\title{
A NEIGHBORHOOD ANALYSIS OF TREE GROWTH AND SURVIVAL IN A HURRICANE-DRIVEN TROPICAL FOREST
}

\author{
María Uriarte,${ }^{1,3}$ Charles D. Canham,${ }^{1} \mathrm{Jill}$ Thompson, ${ }^{2}$ and Jess K. Zimmerman ${ }^{2}$ \\ ${ }^{1}$ Institute of Ecosystem Studies, P.O. Box AB, Millbrook, New York 12545 USA \\ ${ }^{2}$ Institute for Tropical Ecosystem Studies, Universidad de Puerto Rico, P.O. Box 23341, \\ San Juan, Puerto Rico 00931-3341 USA
}

\begin{abstract}
We present a likelihood-based regression method that was developed to analyze the effects of neighborhood competitive interactions and hurricane damage on tree growth and survival. The purpose of the method is to provide robust parameter estimates for a spatially explicit forest simulator and to gain insight into the processes that drive the patterns of species abundance in tropical forests. We test the method using census data from the 16-ha Luquillo Forest Dynamics Plot in Puerto Rico and describe effects of the spatial configuration, sizes, and species of neighboring trees on the growth and survival of 12 dominant tree species representing a variety of life history strategies. Variation in sizedependent growth and mortality suggests a complex relationship between size, growth, and survival under different regimes of light availability. Crowding effects on growth and survival appear to be idiosyncratic to each individual species, and with the exception of pioneers, there is little commonality among species that share similar life histories.

We also explain the implications of differential susceptibility to hurricane damage on species' growth and survival and on their ability to respond to damage to neighboring trees. Tree species in the Luquillo Forest Dynamics Plot differ strikingly in both their susceptibility to hurricane disturbance and the nature of their recovery from wind disturbance, through response of both adult plants and juveniles to enhanced resource availability. At the stand level, intense competitive thinning of densely packed saplings that grew after hurricane damage accounted for the majority of post-hurricane mortality, particularly for shadeintolerant species. At the individual species level, effects of previous hurricane damage on growth and survival depended primarily on variation in the quantity and quality of hurricane damage sustained by target species and their interaction with life history characteristics of these individual species.

Finally, we compare models that make different assumptions about the effects of competing species on tree growth and survival (e.g., equivalence of competitors vs. distinct species-specific effects). Size effects alone could not account for growth and survival for the majority of target species. Our results also demonstrate that competing species have distinct per capita effects on growth of dominant target species. In contrast, we found moderate support for a model that assumed functional equivalence of competitors on survival.
\end{abstract}

Key words: competitive coefficient; equivalent competitors; growth, size-dependent; hurricane disturbance; Luquillo Forest Dynamics Plot, Puerto Rico; mortality, size-dependent; neighborhood effects; neutral theory.

\section{INTRODUCTION}

Tropical forests are repositories of much of the world's biodiversity and play a crucial role in the regulation of global climate. They are also under tremendous pressure from human development. Understanding the dynamics of tree growth and survival is central to both the ecology and management of these forest resources. The spatial and temporal scales of change in tree populations require the use of models to extrapolate from small scale, short-term measurements to realistic spatial and temporal realms (Botkin et al.

Manuscript received 24 March 2003; revised 22 December 2003; accepted 30 December 2003; final version received 26 January 2004. Corresponding Editor: D. L. Urban.

${ }^{3}$ E-mail: UriarteM@ecostudies.org
1972, Shugart and West 1977, Pacala et al. 1996). Forest modeling, coupled with well-designed field studies, can provide a useful tool for assessing the influence of natural and anthropogenic processes on forest composition and structure.

One successful class of forest models uses a spatially explicit approach to predict the performance of individual trees based on the characteristics of the focal tree (i.e., size and taxonomic identity) and depletion of local resources by neighbors (Pacala et al. 1996). Although this class of models has both predictive power and practical applications, a focus on neighborhood interactions alone may fail to provide insight into the processes that drive the relative abundance and diversity of species in plant communities, particularly in highly diverse tropical forests (Hubbell 2001). Un- 
doubtedly, the focus on neighborhood interactions must bias our understanding of the ecological and evolutionary factors that drive plant community dynamics.

From an ecological point of view, a focus on neighborhood interactions may fail to capture and measure the effects of infrequent events (i.e., periodic natural disturbances such as hurricanes or fires). These infrequent events may be more important to understanding the way a particular system works than the day-to-day factors that control dynamics on a neighborhood scale (Tilman 1988). For instance, coexistence of a large number of species in Caribbean forests has often been attributed to density-independent recruitment of species after hurricanes (Vandermeer et al. 1996). Understanding how disturbance interacts with neighborhoodscale processes is crucial to the development of realistic forest models. Neighborhood forest models can act as links between processes at the scale of individual trees and disturbance dynamics at stand and landscape scales (Frelich and Reich 1999).

From an evolutionary point of view, the bias towards neighborhood-scale studies may favor a particular view of the world that ascribes great importance to processes that matter at these scales (e.g., plant competition), but that may be largely irrelevant over evolutionary time or across broad geographic ranges (Hubbell 2001). In fact, Hubbell (2001) has forcefully argued that patterns of relative abundance in tropical forests support the idea that plant communities are non-equilibrium (neutral) assemblages undergoing continuous taxonomic turnover with little coevolution between competitors. This "neutral" view of plant communities assumes that all coexisting species have equivalent per capita fitness (i.e., all individuals of all species have equal probabilities of birth and death), a patently incorrect assumption. Hubbell (2001) proposes that actual data from natural communities support his neutral model because coexisting species differentiate into niches along life history tradeoffs and that, in fact, this differentiation promotes high species diversity in tropical forests.

One obvious way in which species differentiate into niches in communities is by the differential competitive effects that they have on their neighbors. Despite the important implications of establishing that species differ in competitive effects for understanding plant communities, there have been very few studies that have compared the magnitude of competitive effects among coexisting species on a standardized basis such as perindividual or per-capita effects (but see Goldberg 1987, Freckleton and Watkinson 2001). Even fewer studies have looked for differences in species competitive effects in forest communities (but see Canham et al. 2004). Neighborhood forest models can be used to examine the nature and importance of these competitive effects without the need for manipulative experiments.

In this paper, we present a likelihood-based regression method that we have developed to analyze the combined effects of (1) neighborhood competitive interactions and (2) hurricane disturbance on tree growth and survival. We use data from the Luquillo Forest Dynamics Plot (LFDP), a permanent 16-ha plot in the Luquillo Mountains of Puerto Rico. Our approach allows us to test hypotheses by using likelihood ratio tests to compare alternate regression models. These new analyses allow us: (1) to empirically quantify the effects of the spatial configuration, size, and species of neighboring trees on the growth and survival of dominant target tree species; (2) to determine the effects of different levels of hurricane damage on the subsequent responses of species to competition, and the effects of hurricane damage to neighbors on their competitive effects on focal trees; and (3) to compare models that make different assumptions about the effects of different competing species on focal tree growth and survival (e.g., equivalence of competitors vs. distinct species-specific effects).

\section{Materials And Methods}

\section{Study area and field methods}

The Luquillo Forest Dynamics Plot (LFDP), previously known as the Hurricane Recovery Plot (Zimmerman et al. 1994), is a 16-ha forest plot (with southwest corner at $18^{\circ} 20^{\prime} \mathrm{N}, 65^{\circ} 49^{\prime} \mathrm{W}$ ) located near El Verde Field Station in the Luquillo Mountains of northeastern Puerto Rico. The plot is $500 \mathrm{~m}$ from north to south and $320 \mathrm{~m}$ from east to west, and is divided into four hundred $20 \times 20 \mathrm{~m}$ quadrats, with each quadrat subdivided into sixteen $5 \times 5 \mathrm{~m}$ subquadrats. Vegetation and topography of this research area are typical of the tabonuco (Dacryodes excelsa) forest zone. The forest is classified as subtropical wet in the Holdridge life zone system (Ewel and Whitmore 1973) and tropical montane in Walsh's (1966) tropical climate system. Rainfall averages $3500 \mathrm{~mm} / \mathrm{yr}$. Elevation ranges from $333 \mathrm{~m}$ to $428 \mathrm{~m}$ above sea level. All of the soils are formed from volcaniclastic rock (Soil Survey Staff 1995). Information from the LFDP contributes to the efforts of the Center for Tropical Forest Science (CTFS, Smithsonian Tropical Research Institute, Washington, D.C., USA) network of large tropical forest plots, a research effort aimed at furthering our understanding of tropical forests (Condit and LaFrankie, in press).

The LFDP is unique among the CTFS sites as it has a history of both land use disturbance and hurricane damage. These two disturbance types interact and influence the species composition and community dynamics in the LFDP. A full description of the land use history of the plot can be found in Thompson et al. (2002). In summary, the northern area (approximately two-thirds of the plot) was disturbed by tree felling and farming until 1934 when the land was purchased by United States Department of Agriculture, Forest Service. The southern third was not farmed and only suffered relatively light disturbance from selective log- 
TABle 1. Percentage of adult stems, maximum dbh, and successional status of 12 dominant species at the Luquillo Forest Dynamics Plot, Puerto Rico.

\begin{tabular}{|c|c|c|c|c|}
\hline Species (code) & Family & $\begin{array}{l}\text { Adult stems in } \\
16 \text {-ha plot }(\%)\end{array}$ & $\begin{array}{l}\text { Maximum } \\
\text { dbh }(\mathrm{cm})\end{array}$ & $\begin{array}{c}\text { Successional } \\
\text { status } \dagger\end{array}$ \\
\hline Alchornea latifolia (ALCLAT) & Euphorbiaceae & 1.5 & 66.0 & secondary \\
\hline Buchenavia tetraphylla (BUCTET) & Combretaceae & 1.3 & 150.78 & secondary \\
\hline Casearia arborea (CASARB) & Flacourtiaceae & 7.9 & 48.7 & secondary \\
\hline Cecropia schreberiana (CECSCH) & Cecropiaceae & 4.0 & 32.2 & pioneer \\
\hline Dacryodes excelsa (DACEXC) & Burseraceae & 7.4 & 82.2 & late \\
\hline Guarea guidonia (GUAGUI) & Meliaceae & 2.2 & 96.3 & late \\
\hline Inga laurina (INGLAU) & Fabaceae & 4.0 & 78.8 & secondary \\
\hline Manilkara bidentata (MANBID) & Sapotaceae & 4.9 & 78.0 & late \\
\hline Prestoea acuminata (PREMON) & Arecaceae & 34.8 & NA & secondary \\
\hline Schefflera morototoni (SCHMOR) & Araliaceae & 1.5 & 75.0 & pioneer \\
\hline Sloanea berteriana (SLOBER) & Elaeocarpaceae & 3.7 & 93.2 & late \\
\hline Tabebuia heterophylla (TABHET) & Bignoniaceae & 2.4 & 69.2 & secondary \\
\hline
\end{tabular}

$\dagger$ The successional status has been determined from Thompson et al. (2002).

ging. Within the last century, major hurricanes struck the LFDP area in 1928 and 1932. After a 66-yr period with relatively little hurricane damage, in 1989 Hurricane Hugo struck the forest causing significant damage (see summary of effects in Walker et al. 1991).

The LFDP was established in 1990. Censuses are carried out every five years and follow CTFS protocols with a few minor modifications (Condit 1998, Thompson et al. 2002). All freestanding woody stems in the LFDP study area are tagged, identified to species, and their diameter at breast height (diameter at $130 \mathrm{~cm}$ above the ground) measured. Trees are identified by sight in the field or from voucher specimens. Nomenclature follows Liogier (1985, 1988, 1994, 1995, 1997). In addition, individuals $>10 \mathrm{~cm}$ in diameter at breast height (dbh) are mapped within the plot. Individuals $<10 \mathrm{~cm}$ dbh are simply assigned to a $5 \times 5 \mathrm{~m}$ subquadrat without determining specific coordinates. For our model, individuals smaller than $10 \mathrm{~cm}$ dbh were assigned random coordinates within their $5 \times 5 \mathrm{~m}$ subquadrats.

The first LFDP census started in 1990, the year after Hurricane Hugo (September 1989). An inventory of all stems $\geq 10 \mathrm{~cm}$ dbh was carried out between July 1990 and February 1992. This included a survey (September 1990 to February 1991) for trees killed or damaged by Hurricane Hugo to prevent loss of data due to decomposition (Zimmerman et al. 1994). Clearly, quantification of hurricane damage includes many qualitative details (e.g., damage to the stem, degree of crown loss). This qualitative assessment of damage must be translated into a relatively simple categorical classification scheme to be useful to our modeling exercise. The scheme must also be relatively simple so as to minimize the number of additional parameters that will have to be estimated. For instance, inclusion of 10 categories of damage would require that each target species contain enough individuals in each damage category to derive robust parameter estimates. For these reasons we settled on a simple, straightforward rationale for three categories of damage: damage for each stem $\geq 10$ $\mathrm{cm}$ dbh was assessed as none (undamaged), medium (a combination of branch damage and crown break with no stem damage), or complete (heavily damaged with stem snapped, root break, or tip up). Completely damaged stems were identified to species from bark and tree form. A second inventory, of all previously unrecorded live stems $\geq 1 \mathrm{~cm} \mathrm{dbh}$, was carried out from May 1992 to September 1993. These two inventories constitute the first census of the LFDP. The second LFDP census was carried out between November 1994 and October 1996. This census consisted of only one survey of all stems $\geq 1 \mathrm{~cm}$ dbh. In addition, the status of each tree, as dead or alive, was recorded in the second census. See Thompson et al. (2002) for details of census methods.

The LFDP contains 89 species of trees with stems $\geq 10 \mathrm{~cm}$ dbh distributed in 72 genera and 38 families (Thompson et al. 2002). Prestoea acuminata, Casearia arborea, and Dacryodes excelsa make up nearly 50\% of all adult stems in the LFDP (Table 1). Other common species include Alchornea latifolia, Buchenavia tetraphylla, Cecropia schreberiana, Guarea guidonia, Inga laurina, Manilkara bidentata, Schefflera morototoni, Sloanea berteriana, and Tabebuia heterophylla. Fortyfive of the 89 tree species in the LFDP are rare $(<1$ stem $\geq 10 \mathrm{~cm} \mathrm{dbh/ha)}$ and $>75 \%$ of species have $<5$ stems/ha.

The rarity of the majority of species at the LFDP presents a special challenge for our modeling efforts. Rare species cannot provide sufficient data for reliable parameter estimation for our model. Thus, we limited our analyses to 12 target species that are relatively common on the LFDP and represent a wide range of life history strategies (Table 1). Even after this simplification, our neighborhood approach requires that we group competing neighbors using criteria that capture their potentially different effects on the growth and survival of target species. Historically, forest modelers have used a variety of grouping criteria including taxonomic affinity, ecological guilds, similar growth dy- 


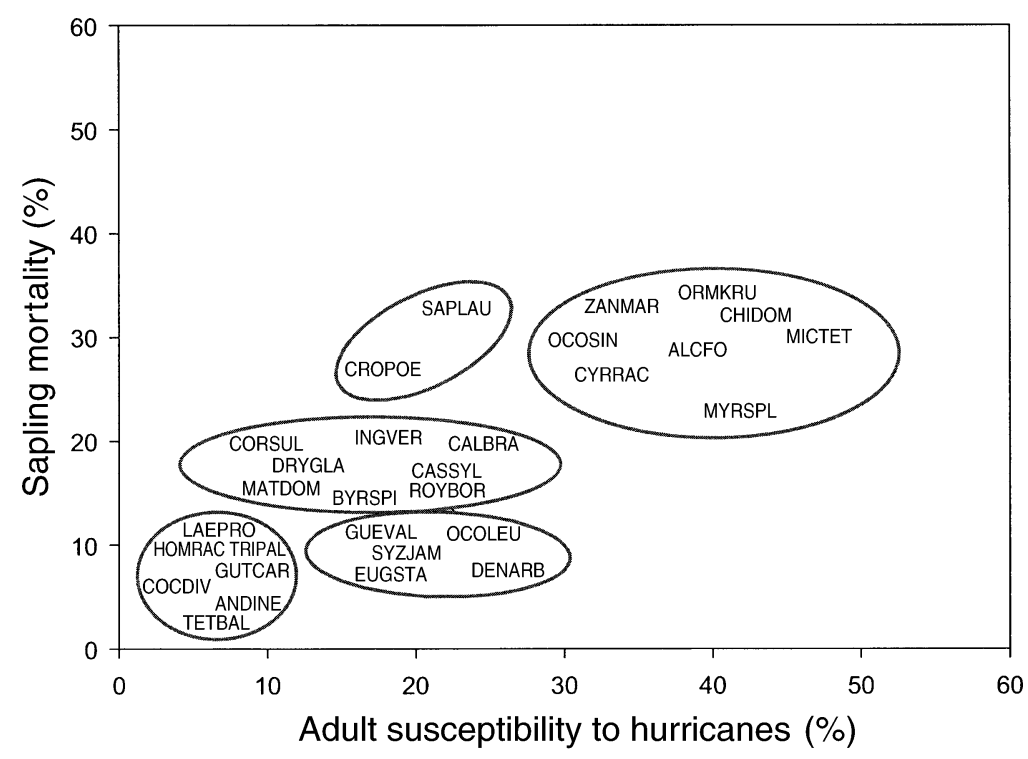

FIG. 1. Sapling mortality vs. adult susceptibility to hurricanes for all species with more than one stem $>10 \mathrm{~cm} \mathrm{dbh/}$ ha. Species inside the same oval were grouped for the neighborhood analyses. A key to these 30 species codes is given in Appendix A.

namics, and several statistical approaches (see review in Vanclay 1995).

\section{Criteria for grouping species}

We classified rare species into six groups. The first group included all species that occurred at densities of $<1$ stem $\geq 10 \mathrm{~cm} \mathrm{dbh/ha} \mathrm{(i.e.,} \mathrm{rare} \mathrm{species;} \mathrm{see} \mathrm{Ap-}$ pendix A). For the remaining scarce species, we used ecological criteria that classified species into five groups according to their response to hurricane damage. Studies in Puerto Rico and elsewhere in the Caribbean suggest that hurricanes play a crucial role in structuring forests in this region (Walker et al. 1991, 1996). For trees, hurricanes cause damage by breakage or uprooting and alter regeneration patterns by increasing light penetration to the understory. Thus, we used two ecological grouping criteria for species present at the LFDP: (1) adult susceptibility to hurricane damage, and (2) the ability of saplings to survive under shaded conditions. The first criterion determines the likelihood that a gap will be formed as a result of damage to an adult tree. The second determines the long-term survival of new saplings that grow after a hurricane damages the canopy and die as the canopy recovers. Data collected in the rapid survey after Hurricane Hugo provided species-specific estimates for the first grouping criteria, susceptibility to hurricane damage. Sapling survival estimates were obtained from species-specific survival in the second census period.

To create the five groups, we plotted susceptibility to hurricane damage (percentage of damaged stems $\geq 10 \mathrm{~cm} \mathrm{dbh}$ ) vs. sapling mortality in response to shading (percentage of dead stems; Fig. 1). Correlation between these two traits was high $\left(R^{2}=0.57\right.$, Fig. 1) lending support to a previous study at the LFDP that found a tradeoff between shade tolerance and frequency of broken stems after Hurricane Hugo (Zimmerman et al. 1994). Species that were similar in these two traits were lumped into single groups yielding five competitor groups (Fig. 1; Appendix A). For instance, Group 2 contained those species with $25-30 \%$ sapling mortality in the shade and $>30 \%$ adult mortality in response to hurricane damage.

We created an additional neighbor species category for the shrub Psychotria berteriana. This shrub became the most numerous species (in total number of stems) at the site after Hurricane Hugo damage, as it responded dramatically to increased light penetration to the understory. Psychotria berteriana rarely reached $>10 \mathrm{~cm}$ dbh but the high densities it attained in the understory led us to believe that it might have important effects on saplings of the canopy tree species.

\section{A maximum-likelihood model of neighborhood competition at the LFDP}

We used data from the LFDP study area to develop and test a spatially explicit, maximum-likelihood, neighborhood model of target tree growth for 11 of the 12 common species at this site (Table 1). Although the palm Prestoea acuminata is the most abundant species at the site, we did not analyze it as a target because diameter measurements do not reflect growth for this species. However, P. acuminata was included as a competing neighbor for all target species. The survival analyses included all 12 species.

Our growth model assumes that each target species has a maximum potential growth rate, which is adjusted to account for the size and taxonomic identity of the 
target, the structure and composition of its neighborhood, and previous hurricane damage to either target or neighbors. A similar approach was used to estimate probability of survival for each individual stem. Our model takes the following form:

$$
\begin{gathered}
g=g_{\mathrm{m}} \phi_{\mathrm{g}} \delta v \\
s=s_{\mathrm{m}} \phi_{\mathrm{s}} \delta v
\end{gathered}
$$

where $g$ and $s$ are predicted growth and survival, respectively, $g_{\mathrm{m}}$ and $s_{\mathrm{m}}$ are maximum potential growth and survival, $\phi$ denotes hurricane effects, $\delta$ is the size effect, and $v$ is the neighborhood effect.

Hurricane effects.-Hurricane effects are taken into account at two levels. Previous hurricane damage affects potential maximum growth rate and probability of survival of the target tree species. Damage also alters the crowding effects of neighbors (see Materials and Methods: Neighborhood effects). The three categories of damage (i.e., none, medium, and complete) recorded after Hurricane Hugo supplied an index of prior hurricane damage to both target and neighbors.

Size effects on growth.-Size effects are calculated using traditional forest growth equations. Potential radial growth is assumed to vary with the dbh of the target tree. We use a lognormal function for the shape of this effect, because it is flexible and supported by both theoretical and empirical evidence (Zeide 1993):

$$
g=g_{\mathrm{m}}^{*} \exp \left(-\frac{1}{2}\right)\left[\frac{\ln \left(\mathrm{dbh} / X_{0}\right)}{X_{\mathrm{b}}}\right]^{2}
$$

where $g_{\mathrm{m}}$ is the maximum potential radial growth (measured in $\mathrm{cm} / \mathrm{yr}$; i.e., at the peak of the lognormal shape), $X_{0}$ is the dbh (of the target tree) at which maximum growth occurs, and $X_{\mathrm{b}}$ determines the breadth of the function. This functional form is flexible enough that for the effective range of trees, the shape can be monotonically increasing (i.e., when $X_{0}$ is very large), decreasing (i.e., when $X_{0}$ is very small), or have a single "hump" and a skew to the left when $X_{0}$ is within the normal range of dbh.

Size effects on survivorship.-There is little agreement in the literature about the shape of the relationship of survivorship and diameter. Higher rates of mortality typically occur at smaller size classes but it is difficult to determine empirically whether this mortality results from size per se (e.g., low buffering capacity in stressful conditions) or from greater crowding at smaller size classes (e.g., high sapling densities in gaps). There is also evidence that rates of mortality increase with age as trees become senescent, and that size-dependent mortality for trees is probably U-shaped (Buchman et al. 1983, Lorimer and Frelich 1984, Harcombe 1987, Monserud and Sterba 1999). We used an equation parallel to Eq. 2a to estimate the mean potential survival of each of the target trees (i.e., in the absence of any crowding or shading), as a function of variation in dbh because it can take a $U$ shape if the estimates of $X_{0}$ and $X_{\mathrm{b}}$ take low values. Probability of survival is estimated as

$$
s=s_{\mathrm{m}}^{*} \exp \left(-\frac{1}{2}\right)\left[\frac{\ln \left(\mathrm{dbh} / X_{0}\right)}{X_{\mathrm{b}}}\right]^{2} .
$$

Neighborhood effects.-Our analysis of the effects of neighborhood crowding relies on the long tradition of distance-dependent analyses of competition, in which target tree growth is analyzed as a function of the sizes and distances to neighboring, competitor trees (e.g., Bella 1971, Hegyi 1974, Lorimer 1983, Wimberly and Bare 1996, Wagner and Radosevich 1998, Vettenranta 1999). The net effect of a neighboring tree on the growth of a target tree of a given species is assumed to vary as a direct function of the size of the neighbor, and as an inverse function of the distance to the neighbor. Most previous studies have assumed that all species of competitors are equivalent. In our analysis, the net effect of an individual neighbor is multiplied by a species-specific scalar $\lambda_{\mathrm{s}}$ that ranges from zero to one and allows for differences among species in their competitive effect on a target tree species. Then, for $i=1 \ldots S$ species and $j$ $=1 \ldots n$ neighbors of species $k$ within a maximum radius $(R)$ around a target tree species, the neighborhood competition index (NCI), an index of net competitive pressure on the target tree, is given by:

$$
\mathrm{NCI}_{\text {focal }, k}=\mathrm{dbh}_{\text {target }, k} \sum_{i=1}^{S} \sum_{j=1}^{n_{k}} \eta_{k} \lambda_{i k} \frac{\left(\mathrm{dbh}_{i j}\right)^{\alpha_{k}}}{\left(\text { distance }_{i j}\right)^{\beta_{k}}}
$$

where $\alpha$ and $\beta$ are estimated by the analyses (rather than set arbitrarily as in previous studies), and determine the shape of the effect of the dbh $(\alpha)$ and the distance $(\beta)$ to the neighbor on NCI. The coefficient $\gamma$ adjusts the effect of NCI when the sensitivity of target trees to crowding is a function of target size. Our computational procedures standardize the values of $\lambda_{\mathrm{s}}$ by setting the highest value that $\lambda$ takes for all neighbors of a given target species equal to 1.0 and dividing the remaining $\lambda_{\mathrm{s}}$ by the maximum value. Our analysis also estimates $R$, the effective neighborhood radius, as a fraction of the maximum neighborhood radius established to be $20 \mathrm{~m}$. To keep the number of parameters in the model manageable, $\alpha$ and $\beta$ are assumed to be equal for all species of neighbors. The parameter $\eta$ is drawn from a vector with three possible values that correspond to the level of previous hurricane damage to a neighboring tree $\left(\eta_{0}\right.$ $=1$ if not damaged, $\eta_{1}<1$ if medium damage, and $\eta_{2}$ $<1$ for complete canopy loss). Neighborhood effects $(v)$ are translated into actual growth by using a negative exponential function of the NCI:

$$
v=\exp -C\left(\frac{\mathrm{NCI}_{i}}{\mathrm{NCI}_{\max }}\right)^{D}
$$

where $C$ and $D$ are species-specific estimated parameters, and $\mathrm{NCI}_{i}$ is the neighborhood competition index for focal sapling $i$, and $\mathrm{NCI}_{\max }$ is the maximum value 
FIG. 2. Effects of neighborhood competition on target growth for two hypothetical species. Species A exhibits a sharp exponential decline in growth with a small amount of crowding. The growth of Species B only declines after a minimum crowding threshold has been reached. The growth multiplier ranges from 0 to 1 and adjusts maximum potential growth to account for neighbor effects.

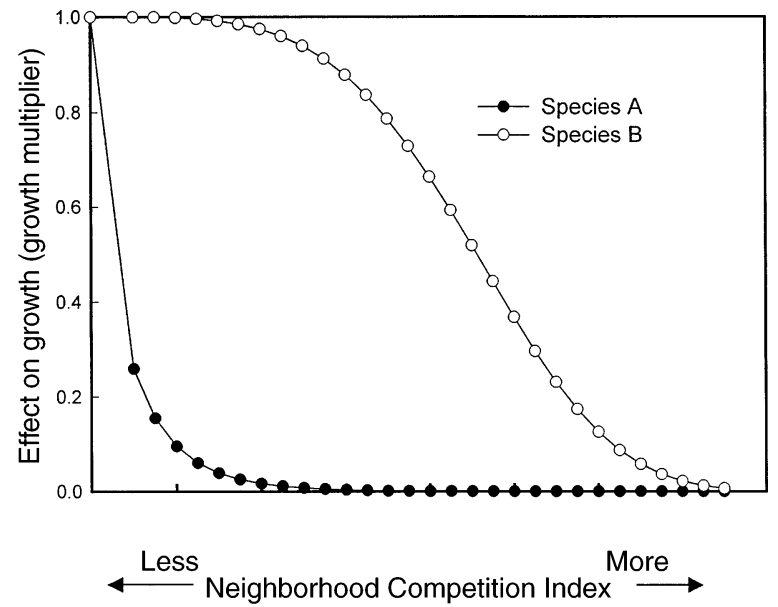

target tree species, the model described by Eq. 1 requires estimation of $n+13$ parameters for $n$ species of competitors. Table 2 provides a complete list and initial range values of all model parameters. Initial parameter ranges were established to provide maximum flexibility while staying within biologically realistic values. For instance, $X_{0}$, the tree size at which maximum growth occurs, was bounded between $0 \mathrm{~cm}$ and $200 \mathrm{~cm}$ as all trees at the LFDP are within this size range.

Eq. 5 provides the likelihood function for observing a given growth in tree $i$. Note that we use the negative of the logarithm of the likelihood, so that the most likely function is the one that makes the negative log likelihood as small as possible. Our likelihood function assumes that the residuals (i.e., the difference between observed and predicted growth) approximate a normal distribution (Mangel and Clark 1997). Thus, parameter values that maximize the log likelihood will be those that minimize the square deviation between observed and predicted values (as in traditional regression analyses):

log likelihood (data/model)

$$
\begin{aligned}
=n[ & \left.\log (\partial)+\frac{1}{2} \log (2 \pi)\right] \\
& +\sum_{i=1}^{n} \frac{\left(\text { observed }_{i}-\text { expected }_{i}\right)^{2}}{2 \partial^{2}} .
\end{aligned}
$$

Eq. 6 provides the likelihood function for probability of survival for our data where $p_{i}$ is the probability of observing that a tree of a given species, size, and neighborhood is alive, and $\left(1-p_{i}\right)$ is the likelihood of observing that the tree died. Thus, the log likelihood of observing the entire data set for a given target species, given a set of parameter values is

$$
\begin{array}{ll}
\log \text { likelihood }(\text { data/model }) & \\
=\sum_{i=1}^{n} \log \left(p_{i}\right) & \text { if tree is alive } \\
\log \left(1-p_{i}\right) & \text { if tree is dead. }
\end{array}
$$

The log likelihoods in Eqs. 5 and 6 assume inde- 
TABLE 2. List and range of parameters included in growth and mortality models. Separate parameters were estimated for each target species.

\begin{tabular}{|c|c|c|c|}
\hline \multicolumn{2}{|l|}{ Growth model } & \multicolumn{2}{|l|}{ Mortality model } \\
\hline Parameter & Range & Parameter & Range \\
\hline Maximum growth $\left(g_{\mathrm{m}}\right)$ & $0-40 \mathrm{~mm}$ & Maximum probability of survival $\left(s_{\mathrm{m}}\right)$ & $0-1$ \\
\hline Hurricane effects on maximum growth $\left(\phi_{\mathrm{g}}\right) \dagger$ & $0-1$ & $\begin{array}{l}\text { Hurricane effects on maximum probability of } \\
\text { survival }\left(\phi_{\mathrm{s}}\right) \dagger\end{array}$ & $0-1$ \\
\hline Effective neighborhood radius $(R)$ & $0-20$ & Effective neighborhood radius $(R)$ & $0-20$ \\
\hline $\begin{array}{l}\text { Size vs. growth } \ddagger \\
\left(X_{0}\right) \\
\left(X_{\mathrm{b}}\right)\end{array}$ & $\begin{array}{l}0-200 \mathrm{~cm} \\
0-20\end{array}$ & $\begin{array}{l}\text { Size vs. probability of survival } \ddagger \\
\left(X_{0}\right) \\
\left(X_{\mathrm{b}}\right)\end{array}$ & $\begin{array}{l}0-200 \mathrm{~cm} \\
0-20\end{array}$ \\
\hline $\begin{array}{l}\text { Neighborhood effects } \\
\quad C \\
D\end{array}$ & $\begin{array}{l}0-10 \\
1-5\end{array}$ & $\begin{array}{l}\text { Neighborhood effects } \\
\quad C \\
D\end{array}$ & $\begin{array}{l}0-10 \\
1-5\end{array}$ \\
\hline Competitive coefficients $\left(\lambda_{i}\right)$ & $0-1$ & Competitive coefficients $\left(\lambda_{i}\right)$ & $0-1$ \\
\hline Effect of neighbor size on target growth $\left(\alpha_{\mathrm{g}}\right)$ & $0-4$ & Effect of neighbor size on target survival $\left(\alpha_{\mathrm{s}}\right)$ & $0-4$ \\
\hline $\begin{array}{l}\text { Effect of distance on neighbor effect on target } \\
\quad \text { growth }\left(\beta_{\mathrm{g}}\right)\end{array}$ & $0-4$ & $\begin{array}{l}\text { Effect of distance on neighbor effect on target } \\
\text { survival }\left(\beta_{\mathrm{s}}\right)\end{array}$ & $0-4$ \\
\hline Sensitivity to crowding $\left(\gamma_{\mathrm{g}}\right)$ & -2 to 2 & Sensitivity to crowding $\left(\gamma_{\mathrm{s}}\right)$ & -2 to 2 \\
\hline Adjustment $(\eta) \S$ & $0-1$ & Adjustment $(\eta) \S$ & $0-1$ \\
\hline
\end{tabular}

pendence among observations (target trees). If present, strong autocorrelation among observations would produce biased underestimates of parameter variance, but both the parameter estimates themselves and comparisons of models using likelihood ratio tests are generally unaffected by spatial autocorrelation among the observations (Hubbell et al. 2001). This is one of the benefits of using likelihood ratio tests for hypothesis testing (i.e., statistical comparison of alternate models).

We used simulated annealing, a global optimization procedure, to determine the most likely parameters (i.e., the parameters that maximize the log likelihood), given our observed data (Goffe et al. 1994). We ran the algorithm for at least 200000 iterations and considered it to have converged if it did not change in likelihood in three temperature drops after the initial 200000 iterations. In general, models with a larger number of parameters converged after a greater number of iterations than simpler models.

Parsimony suggests the strategy of systematically reducing the number of distinct parameters to the simplest model that is not a significantly worse fit than any more complicated model (for instance, by lumping species that have similar life histories, or dropping terms like size effects if they do not appear to improve the likelihood of the model). One of our motivations for this study was to provide parameter estimates to model the long-term effects of neighborhood competition on forest dynamics (using SORTIE; Pacala et al. 1996). Thus, one of our goals was to determine the most likely parameter values for each species given our data. For each target species analysis, we first tested whether including the effects of hurricanes on either targets or neighbors (parameters $\phi$ and $\eta$ in Eqs. 1 and 3) improved the predictive ability of the model.

A secondary motivation for this study was to explore the nature of competitive interactions in the community. Thus, we also explicitly tested five alternate, nested models that made different assumptions about the nature of competitive interactions between target species (Tables 3, 4). (1) The "full" model assumed that each competing species (i.e., species listed in Table 1 plus the seven species groups) had a distinct and unique effect on each target. (2) For each target species, we then grouped competitors that had similar estimated competitive coefficients $\left(\lambda_{i}\right)$ in the full model. We used these parsimonious groupings of species to lower the number of parameters by considering species in the same groups to have identical competitive effects $\left(\lambda_{i}\right)$ on the target. For instance, if the competitive effects of Caseria arborea and Dacryodes excelsa on Cecropia schreberiana were similar (i.e., they had overlapping estimates of competitive coefficients, $\lambda_{i}$ 's), we tested a "mixed" model that grouped these two species in the same competitor group and had one less parameter than the "full" model. Note that these "mixed" model species groupings are distinct from ecological groupings that were created prior to the analyses (see Materials and Methods: Criteria for grouping species). (3) We also tested a third model that differentiated only between conspecific and heterospecific neighbors. (4) Our simplest competition model assumed that all competitors had equivalent effects on the target regardless of taxonomic identity. There are a number of very inter- 
TABLE 3. Likelihood analysis results (L) and goodness of fit $\left(R^{2}\right)$ for six models of growth for 11 dominant target species at the Luquillo Forest Dynamics Plot.

\begin{tabular}{|c|c|c|c|c|c|c|c|}
\hline Target species & Statistic & $\begin{array}{l}\text { Full model } \\
+ \text { hurricane }\end{array}$ & $\begin{array}{l}\text { Full model } \\
\text { - hurricane }\end{array}$ & Mixed model $\dagger$ & $\begin{array}{c}\text { Conspecific } \\
\text { vs. } \\
\text { heterospecific }\end{array}$ & $\begin{array}{l}\text { Equivalent } \\
\text { competitor }\end{array}$ & $\begin{array}{l}\text { Size effects } \\
\text { only }\end{array}$ \\
\hline \multirow[t]{2}{*}{ Alchornea latifolia } & $\mathrm{L}$ & -1065.48 & -1066.84 & -1069.38 & -1091.88 & -1091.79 & -1101.64 \\
\hline & $R^{2}$ & $0.27(32)$ & $0.26(28)$ & $0.25(14)$ & $0.18(11)$ & $0.18(9)$ & $0.15(3)$ \\
\hline \multirow{2}{*}{ Buchenavia tetraphylla } & $\mathrm{L}$ & -517.91 & -509.98 & -509.67 & -535.49 & -537.47 & -549.76 \\
\hline & $R^{2}$ & $0.35(32)$ & $0.41(28)$ & $0.40(15)$ & $0.22(11)$ & $0.21(9)$ & $0.10(3)$ \\
\hline \multirow{2}{*}{ Casearia arborea } & $\mathrm{L}$ & -6629.46 & -6633.98 & -6629.09 & -6681.30 & -6688.82 & -6723.10 \\
\hline & $R^{2}$ & & & & & & 0.09 (3) \\
\hline \multirow{2}{*}{ Cecropia schreberiana } & $\mathrm{L}$ & -12445.71 & -12457.94 & -12451.6 & -12512.90 & -12518.01 & -12753.27 \\
\hline & $R^{2}$ & & & & & 0.2 & $0.19(5)$ \\
\hline \multirow[t]{2}{*}{ Dacryodes excelsa } & $\mathrm{L}$ & -2964.38 & -2979.90 & -2961.65 & -2999.47 & -3046.68 & -3157.36 \\
\hline & $R^{2}$ & $0.34(32)$ & $0.32(28)$ & $0.34(18)$ & $0.30(15)$ & $0.25(13)$ & $0.11(5)$ \\
\hline \multirow[t]{2}{*}{ Guarea guidonia } & $\mathrm{L}$ & -1230.00 & -1243.38 & -1225.78 & -1247.83 & -1255.64 & -1281.58 \\
\hline & $R^{2}$ & & $0.24(28)$ & 0.28 (19) & $0.23(15)$ & $0.21(13)$ & $0.12(5)$ \\
\hline \multirow[t]{2}{*}{ Inga laurina } & $\mathrm{L}$ & -2038.09 & -2044.91 & -2047.77 & -2070.56 & -2073.00 & -2093.10 \\
\hline & $R^{2}$ & 0.2 & & 18) & 02 & 0.21 & $0.19(5)$ \\
\hline \multirow[t]{2}{*}{ Manilkara bidentata } & $\mathrm{L}$ & -2415.18 & -2434.90 & -2411.83 & -2445.09 & -2451.39 & -2500.07 \\
\hline & $R^{2}$ & & & & 0.23 & & $0.16(5)$ \\
\hline \multirow[t]{2}{*}{ Schefflera morototoni } & $\mathrm{L}$ & -4449.37 & -4445.10 & -4435.57 & -4485.06 & -4503.66 & -4543.98 \\
\hline & $R^{2}$ & $0.32(32)$ & $0.32(28)$ & $0.33(14)$ & $0.29(15)$ & $0.28(9)$ & $0.24(3)$ \\
\hline \multirow[t]{2}{*}{ Sloanea berteriana } & $\mathrm{L}$ & -3659.61 & -3674.22 & -3660.93 & -3683.28 & -3684.59 & -3720.11 \\
\hline & $R^{2}$ & $0.11(32)$ & & $0.10(18)$ & 0.09 (15) & $0.08(13)$ & $0.05(5)$ \\
\hline \multirow[t]{2}{*}{ Tabebuia heterophylla } & $\mathrm{L}$ & -739.42 & -738.49 & -734.98 & -747.38 & -747.09 & -747.89 \\
\hline & $R^{2}$ & $0.13(32)$ & $0.13(28)$ & $0.14(14)$ & $0.09(11)$ & $0.09(9)$ & $0.09(3)$ \\
\hline
\end{tabular}

Notes: The first full model considers the effect of previous hurricane damage to target and neighbors. The second full model does not include hurricane damage. The mixed model groups species with similar competitive effects on the target. The fourth model differentiates between conspecific and heterospecific competitors. The equivalent competitor model considers all species to have the same competitive effect. The size model does not include competition. The number of parameters for each model is given in parentheses.

$\dagger$ The mixed model was the most parsimonious model for all species.

esting and fundamental hypotheses embedded in these tests: one of the most basic is functional equivalence of competitors. (5) Finally, a model that included only size effects provided a null model against which to compare the significance and magnitude of competitive interactions in determining tree growth and survival. Appendix B lists all models included in the analyses.

Alternate models were compared using likelihood ratio tests (Hilborn and Mangel 1997), with degrees of freedom equal to the difference in the number of parameters between the two nested models. This method tests whether the inclusion of additional parameters in the model results in a significant improvement in the likelihood. For normally distributed residuals, this is also strictly analogous to whether there is a significant improvement in goodness of fit as measured by $R^{2}$. The tests thus allow explicit tests of the hypotheses that are implicit in the comparison of alternate models. For example, to test whether there are significant differences among species of neighbors in their effect on a target tree species, we compared the likelihood of a model with all species groups ("full" model) with a simpler model in which all neighboring trees were lumped into one group ("equivalent competitor model"). We also compared these "extreme" models with intermediate nested models that distinguished between conspecific and heterospecific competitors or considered functional groupings of competitors ("mixed" model).
We calculated asymptotic 95\% support limits (Hillborn and Mangel 1997) for each of the parameters by holding all other parameters at their maximum-likelihood value and then systematically increasing or decreasing the parameter of interest until the likelihood of the resulting model was significantly worse (at the $5 \%$ alpha level) than the maximum-likelihood model, using twice the difference in log likelihoods of the two models as a chi square statistic with $1 \mathrm{df}$ (i.e., a likelihood ratio test; Hillborn and Mangel 1997).

We assessed the goodness of fit of our growth models using traditional regression methods $\left(R^{2}\right)$, and the slope of the regression (with a zero intercept) of observed radial growth on predicted radial growth was used to measure bias, with an unbiased model having a slope of one. For mortality analyses, we had to choose from a variety of techniques that are used to assess the goodness of fit of logistic regression models (Demaris 1992). We used the following approach: (1) for each tree in the dataset we calculated the predicted probability of survival given the maximum-likelihood parameters, and (2) using the entire dataset, we then grouped the predicted probabilities of survival into classes $(0-10 \%, 10-20 \%$, and so forth) and computed the percentage of trees in that category that were actually alive. Thus, for individuals predicted to have a $0-10 \%$ probability of survival, a model that fits well will have $\sim 5 \%$ of the individuals alive. This method 
TABLE 4. Likelihood analyses results (L) for six models of survival for 12 dominant target species at the Luquillo Forest Dynamics Plot.

\begin{tabular}{|c|c|c|c|c|c|c|c|}
\hline Target species & Statistic & $\begin{array}{l}\text { Full model } \\
+ \text { hurricane }\end{array}$ & $\begin{array}{l}\text { Full model } \\
- \text { hurricane }\end{array}$ & Mixed model & $\begin{array}{c}\text { Conspecific } \\
\text { vs. } \\
\text { heterospecific }\end{array}$ & $\begin{array}{l}\text { Equivalent } \\
\text { competitor }\end{array}$ & $\begin{array}{l}\text { Size effects } \\
\text { only }\end{array}$ \\
\hline Alchornea latifolia & $\mathrm{L}$ & $\begin{array}{c}-663.90 \\
(32)\end{array}$ & $\begin{array}{c}-679.82 \\
(28)\end{array}$ & $\begin{array}{c}-656.99 \\
(18)\end{array}$ & $\begin{array}{l}-652.87 \dagger \\
(15)\end{array}$ & $\begin{array}{c}-669.37 \\
(13)\end{array}$ & $\begin{array}{c}-693.93 \\
(5)\end{array}$ \\
\hline Buchenavia tetraphylla & $\mathrm{L}$ & $\begin{array}{c}-150.02 \\
(32)\end{array}$ & $\begin{array}{c}-157.82 \\
(28)\end{array}$ & $\begin{array}{l}-145.78 \dagger \\
(18)\end{array}$ & $\begin{array}{c}-153.46 \\
(15)\end{array}$ & $\begin{array}{c}-162.77 \\
(13)\end{array}$ & $\begin{array}{c}-170.49 \\
(5)\end{array}$ \\
\hline Casearia arborea & $\mathrm{L}$ & $\begin{array}{c}-2892.41 \\
(32)\end{array}$ & $\begin{array}{c}-2971.35 \\
(28)\end{array}$ & $\begin{array}{c}-2868.04 \dagger \\
(18)\end{array}$ & $\begin{array}{c}-2874.57 \\
(15)\end{array}$ & $\begin{array}{c}-2896.8 \\
(13)\end{array}$ & $\begin{array}{c}-2981.74 \\
(5)\end{array}$ \\
\hline Cecropia schreberiana & $\mathrm{L}$ & $\begin{array}{c}-4186.22 \\
(32)\end{array}$ & $\begin{array}{c}-4207.76 \\
(28)\end{array}$ & $\begin{array}{c}-4187.9 \dagger \\
(19)\end{array}$ & $\begin{array}{c}-4321.07 \\
(15)\end{array}$ & $\begin{array}{c}-4357.84 \\
(13)\end{array}$ & $\begin{array}{c}-4439.86 \\
(5)\end{array}$ \\
\hline Dacryodes excelsa & $\mathrm{L}$ & $\begin{array}{c}-167.12 \\
(32)\end{array}$ & $\begin{array}{l}-206.70 \\
(28)\end{array}$ & $\begin{array}{l}-165.05 \\
(18)\end{array}$ & $\begin{array}{l}-163.24 \\
(15)\end{array}$ & $\begin{array}{l}-165.82 \dagger \\
(13)\end{array}$ & $\begin{array}{c}-222.43 \\
(5)\end{array}$ \\
\hline Guarea guidonia & $\mathrm{L}$ & $\begin{array}{c}-469.61 \\
(32)\end{array}$ & $\begin{array}{c}-478.47 \\
(28)\end{array}$ & $\begin{array}{c}-470.10 \dagger \\
\text { (19) }\end{array}$ & $\begin{array}{c}-476.15 \\
(15)\end{array}$ & $\begin{array}{l}-520.09 \\
(13)\end{array}$ & $\begin{array}{l}-536.59 \\
(5)\end{array}$ \\
\hline Inga laurina & $\mathrm{L}$ & $\begin{array}{c}-528.34 \\
(32)\end{array}$ & $\begin{array}{l}-611.55 \\
(28)\end{array}$ & $\begin{array}{c}-527.83 \\
(18)\end{array}$ & $\begin{array}{c}-530.53 \\
(15)\end{array}$ & $\begin{array}{l}-528.35 \dagger \\
(13)\end{array}$ & $\begin{array}{c}-616.01 \\
(5)\end{array}$ \\
\hline Manilkara bidentata & $\mathrm{L}$ & $\begin{array}{l}-246.46 \\
(32)\end{array}$ & $\begin{array}{l}-272.33 \\
(28)\end{array}$ & $\begin{array}{c}-246.4 \\
(18)\end{array}$ & $\begin{array}{c}-247.93 \\
(15)\end{array}$ & $\begin{array}{l}-248.88 \dagger \\
(13)\end{array}$ & $\begin{array}{l}-280.05 \\
(5)\end{array}$ \\
\hline Prestoea acuminata & $\mathrm{L}$ & $\begin{array}{c}-1362.80 \\
(32)\end{array}$ & $\begin{array}{c}-1906.31 \\
(28)\end{array}$ & $\begin{array}{c}-1359.46 \dagger \\
(18)\end{array}$ & $\begin{array}{c}-1403.22 \\
(15)\end{array}$ & $\begin{array}{c}-1403.78 \\
(13)\end{array}$ & $\begin{array}{c}-2000.69 \\
(5)\end{array}$ \\
\hline Schefflera morototoni & $\mathrm{L}$ & $\begin{array}{c}-2282.12 \\
(32)\end{array}$ & $\begin{array}{l}-2311.04 \\
(28)\end{array}$ & $-2262.73 \dagger$ & $\begin{array}{c}-2362.06 \\
(15)\end{array}$ & $\begin{array}{c}-2433.66 \\
(13)\end{array}$ & $\begin{array}{c}-2495.81 \\
(5)\end{array}$ \\
\hline Sloanea berteriana & $\mathrm{L}$ & $\begin{array}{c}-803.66 \\
(32)\end{array}$ & $\begin{array}{l}-815.06 \\
(28)\end{array}$ & $\begin{array}{l}-802.99 \\
(19)\end{array}$ & $\begin{array}{c}-803.49 \\
(15)\end{array}$ & $\begin{array}{l}-803.45 \dagger \\
(13)\end{array}$ & $\begin{array}{c}-818.64 \\
(5)\end{array}$ \\
\hline Tabebuia heterophylla & $\mathrm{L}$ & $\begin{array}{l}-257.74 \\
(32)\end{array}$ & $\begin{array}{l}-289.75 \\
(28)\end{array}$ & $\begin{array}{l}-258.79 \\
(19)\end{array}$ & $\begin{array}{l}-259.05 \\
(15)\end{array}$ & $\begin{array}{l}-261.17 \dagger \\
(13)\end{array}$ & $\begin{array}{l}-294.86 \\
(5)\end{array}$ \\
\hline
\end{tabular}

Notes: The first full model considers the effect of previous hurricane damage to target and neighbors. The second full model does not include hurricane damage. The mixed model groups species with similar competitive effects on the target. The fourth model differentiates between conspecific and heterospecific competitors. The equivalent competitor model considers all species to have the same competitive effect. The size model does not include competition. The number of parameters for each model appears in parentheses.

$\dagger$ The most parsimonious model.

gives us a visual way to compare "observed" with "expected" given the model. The benefit of this approach is that it is easy to see if the model fits equally well across the entire range of predicted probabilities or whether it falls apart within some particular ranges.

\section{REsUlts}

\section{Likelihood and goodness of fit of alternate growth and survival models}

Growth.-We estimated maximum-likelihood parameter values for a series of alternate, nested growth models for the selected target species (Table 3). For all 11 target species, the best model identified different functional groupings of species (mixed model option; Table 3). For Cecropia schreberiana, Dacryodes excelsa, Guarea guidonia, Inga laurina, Manilkara bidentata, and Sloanea berteriana, the most parsimonious growth model included effects of hurricane damage (i.e., the difference in log likelihood between the "full model" with hurricane effects and the "full model without hurricane effects" was greater than the $P=$ 0.05 critical value for a likelihood ratio test with $4 \mathrm{df}$ ). For the remainder of target species, the simpler model without hurricane effects was not significantly lower in likelihood than the full model (i.e., difference in log likelihood between models with and without hurricane damage was $<4.74$ ).

All of the models produced unbiased estimates of radial growth, with a slope of 1 between predicted and observed, and symmetrically distributed residuals. The percentage of variance explained by the best models ranged from only $9 \%$ for Tabebuia heterophylla to $40 \%$ in Buchenavia tetraphylla (Table 3). For all species, the variance in radial growth was proportional to the mean. Neither the likelihood estimation methods we used to fit the models, nor the likelihood ratio statistics we used to compare the models, are particularly sensitive to heteroscedasticity, so we did not attempt to transform the growth rates to homogenize the variance before fitting the models.

Survival.-We also compared several nested survival models using likelihood ratio tests. For five of the species (Dacryodes excelsa, Inga laurina, Manilkara bidentata, Sloanea berteriana, and Tabebuia heterophylla), a simplified model that ignored differences in the identities of neighboring species (i.e., estimated a single competitive effect regardless of species of neighbor) was the most parsimonious model (i.e., did not have significantly lower likelihood and had fewer parameters than the model that estimated separate competitive coefficient values for each species of neighbor; 

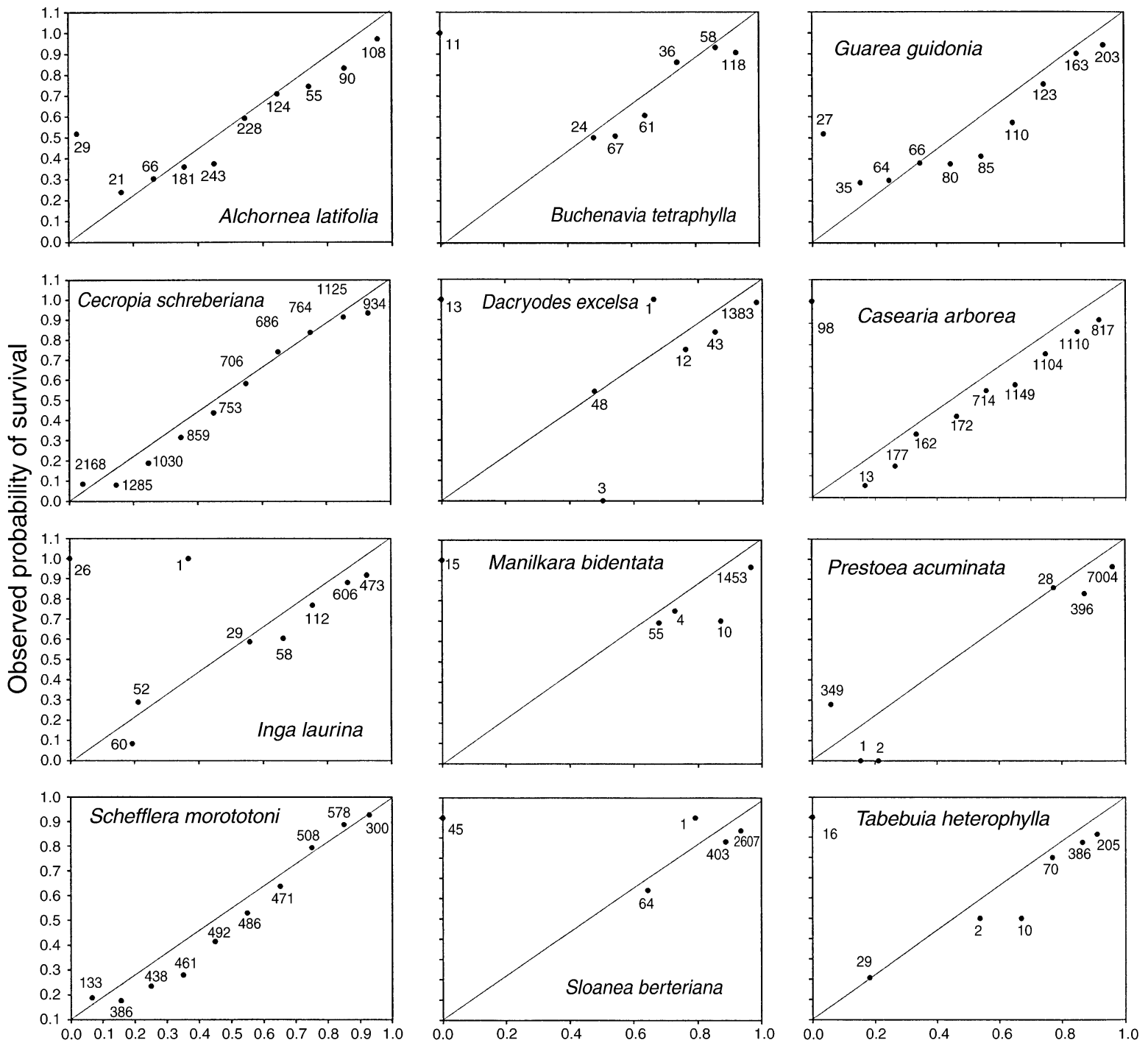

Predicted probability of survival

FIG. 3. Goodness of fit of the maximum-likelihood analysis of probability of survival for 12 target species as a function of hurricane damage, size of the target, and crowding effects. We used the following approach: (a) For each tree in the data set we calculated the predicted probability of survival given the maximum-likelihood parameters, and (b) using the entire data set, we then grouped the predicted probabilities of survival into classes $(0-10 \%, 10-20 \%$, and so forth) and computed the percentage of trees in that category that were actually alive (observed). The number of observations for each probability of survival category is indicated next to each data point.

Table 4). For the remaining seven species (Alchornea latifolia, Buchenavia tetraphylla, Casearia arborea, Cecropia schreberiana, Guarea guidonia, Prestoea acuminata and Schefflera morototoni), models that distinguished between conspecific and heterospecific competitors or considered functional groupings of competitors provided a significantly better fit. For all 12 species, the most likely survival model included effects of hurricane damage (Table 4).

In general, our method of likelihood estimation produced a good fit to the overall data set. The fit was particularly good throughout the range of predicted mortality values for species with high mortality rates (e.g., pioneers such as Cecropia schreberiana and Schefflera morototoni; Fig. 3). The relationship between observed and predicted probability of survival breaks down at the low end of the range for secondary and late-successional species (i.e., Inga laurina or Dacryodes excelsa in Fig. 3). Most of these species had few dead individuals and thus our fitted model did not represent the lower range of predicted survival values. 
FIG. 4. Predicted potential diameter growth as a function of target size using Eq. 2a and parameters reported in Table 3. See Table 1 for scientific names of target species. Pioneer species are indicated with open symbols, secondary species with gray symbols, and late-successional species with solid symbols. Each species is plotted in its actual range of dbh values.

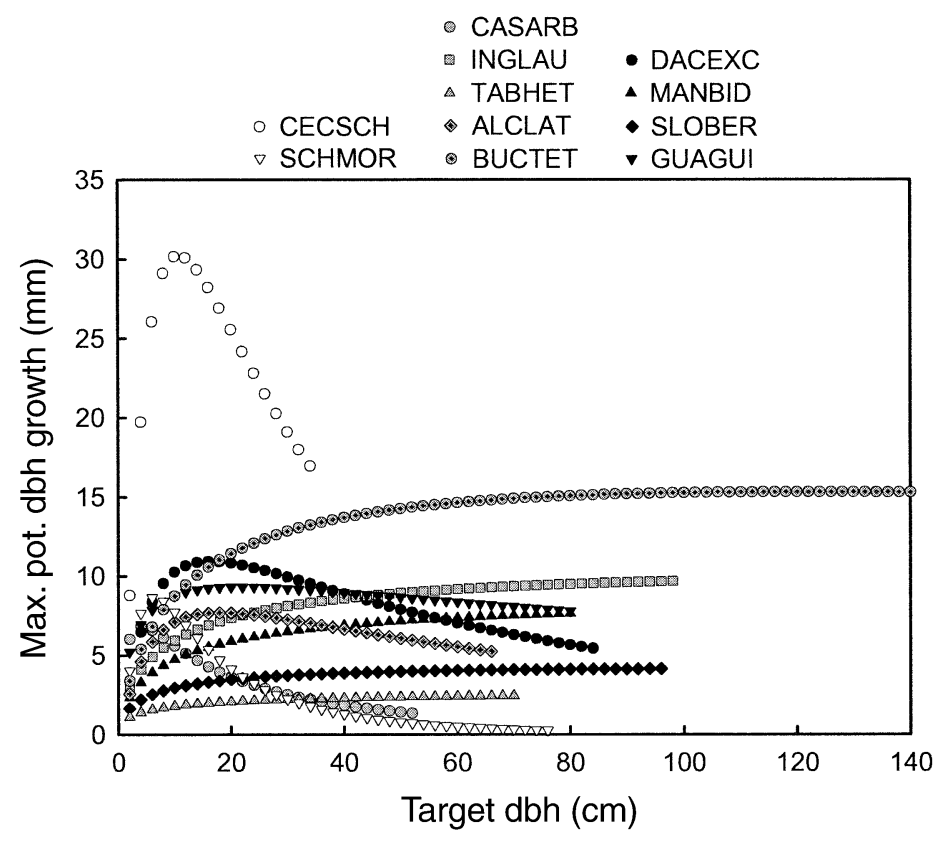

Effects of dbh on potential radial growth and survivorship

Growth.-Our analyses allowed us to estimate the mean potential radial growth of trees of each of the target trees (i.e., in the absence of any crowding or shading) as a function of variation in dbh (Fig. 4). In effect, the predicted mean growth rates in Fig. 4 are the expected growth rates for a tree completely released from competition with neighboring trees. The shapes of the relationships shown in Fig. 4 are controlled by three of the estimated parameters in Table 5: Maximum Growth, which determines the height of the peak; $X_{0}$, which determines the dbh at which peak growth occurs; and $X_{\mathrm{b}}$, which determines the breadth of the distribution. For instance, the pioneer Cecropia schreberiana was predicted to have highest mean, potential, radial growth of $30.23 \mathrm{~mm} / \mathrm{yr}$ (Maximum Growth). Maximum growth occurred at a relatively small size $\left(X_{0}=10.75 \mathrm{~cm} \mathrm{dbh}\right)$, and there was a rapid decline in growth with increasing size $\left(X_{\mathrm{b}}=1.07\right.$; Table 5 and Fig. 4). The function for Schefflera morototoni, the other pioneer species, was similar in shape, with lower maximum growth. The peak of growth for Dacryodes excelsa (a late-successional species) and for Alchornea latifolia and Casearia arborea (secondary-successional species) occurred at a larger size or the shape of the distribution was considerably flatter than for pioneer species. The remainder of target species had greater growth at large size classes and the function was, in fact, fairly flat across the range of canopy tree sizes.

Survival.-There has been relatively little prior research on the fundamental shape of the relationship of mortality to tree diameter. Greater rates of mortality typically occur at smaller size classes but it is difficult to determine empirically whether this mortality results from size per se or from typically greater crowding at smaller size classes. Our results (likelihood ratio tests) clearly indicate that size effects alone are not sufficient to explain survival for the majority of target species (Table 4). Moreover, our approach allowed us to estimate the mean potential survival of trees of each of the target trees (i.e., in the absence of any crowding or shading), as a function of variation in dbh (Fig. 5). Thus, Fig. 5 illustrates the predicted species-specific survival for a tree completely released from competition with neighboring trees. The shapes of the relationships shown in Fig. 5 are controlled by three of the estimated parameters in Table 6: Maximum Probability Survival, which determines the height of the peak; $X_{0}$, which determines the dbh at which peak survival occurs; and $X_{\mathrm{b}}$, which determines the breadth of the distribution. For example, the pioneer species Cecropia schreberiana was predicted to have highest mean potential survival of $0.99 / \mathrm{yr}$ (Maximum Probability of Survival). As with growth for this species, maximum survival occurred at a small size $\left(X_{0}=8.45\right.$ $\mathrm{cm} \mathrm{dbh})$, and declined rapidly as stems increased in $\mathrm{dbh}\left(X_{\mathrm{b}}=1.85\right.$; Table 6$)$. The function for survival of the two pioneer species, Schefflera morototoni and Cecropia schreberiana, and for the secondary-successional species Casearia arborea, showed that survival rate declined steeply as stem diameter increased. For the remainder of the target species there is little evidence that size affects probability of survival.

\section{Effects of neighboring tree distance and size on degree of crowding}

Growth.-The Neighborhood Competition Index (NCI) sums the effects of all neighboring trees within 
TABLE 5. Parameter estimates and support intervals for the most likely growth models for 11 dominant trees.

\begin{tabular}{|c|c|c|c|c|c|}
\hline Parameter & ALCLAT & BUCTET & CASARB & $\mathrm{CECSCH}$ & DACEXC \\
\hline$n$ & 506 & 195 & 3150 & 4067 & 1306 \\
\hline Maximum growth & 7.75 & 15.31 & 6.84 & 30.23 & 10.94 \\
\hline rate $(\mathrm{mm} / \mathrm{yr})$ & $(7.55-7.78)$ & $(15.15-15.45)$ & $(6.78-6.98)$ & $(29.92-30.53)$ & $(10.83-11.05)$ \\
\hline$C$ & 1.98 & 4.57 & 4.69 & 7.18 & 4.14 \\
\hline & $(1.90-1.2)$ & $(4.34-4.61)$ & $(4.55-4.73)$ & $(7.11-7.25)$ & $(4.06-4.18)$ \\
\hline$D$ & 1.0 & 1.00 & 1.26 & 1.63 & 1.0 \\
\hline & $(1-1.01)$ & $(1-1.01)$ & $(1.25-1.29)$ & $(1.61-1.64)$ & $(1-1.01)$ \\
\hline Radius (m & 12 & 3.2 & 19.7 & 19.84 & 18.8 \\
\hline$\alpha$ & $\begin{array}{c}(11.8-12.2) \\
2.81\end{array}$ & $\begin{array}{c}(3.12-3.2) \\
1.75\end{array}$ & $\begin{array}{c}(19.6-19.9) \\
1.33\end{array}$ & $\begin{array}{c}(19.6-19.8) \\
1.22\end{array}$ & $\begin{array}{c}(18.6-19) \\
179\end{array}$ \\
\hline & $(2.78-2.87)$ & $(1.74-1.78)$ & $(1.31-1.35)$ & $(1.21-1.25)$ & $(1.77-1.81)$ \\
\hline$\beta$ & 0.50 & 0.09 & 0.75 & 0.48 & 0.86 \\
\hline & $(0.47-0.51)$ & $(0.05-0.10)$ & $(0.74-0.77)$ & $(0.47-0.49)$ & $(0.85-0.87)$ \\
\hline & 17.99 & 122.23 & 4.07 & 10.75 & 16.43 \\
\hline$X_{0}(\mathrm{~cm})$ & $(17.81-18.89)$ & $(119.79-123.46)$ & $(4.04-4.12)$ & $(10.43-10.86)$ & $(16.27-17.09)$ \\
\hline$X_{\mathrm{b}}$ & 1.48 & 2.36 & 1.41 & 1.07 & 1.38 \\
\hline & $(1.45-1.50)$ & $(2.34-2.48)$ & $(1.39-1.44)$ & $(1.05-1.11)$ & $(1.34-1.39)$ \\
\hline $\operatorname{Gamma}(\gamma)$ & $\begin{array}{c}0.43 \\
(0.41-0.43)\end{array}$ & $\begin{array}{c}0.36 \\
(0.36 \text { to } 0.37)\end{array}$ & $\begin{array}{c}-0.40 \\
(-0.41 \text { to }-0.39)\end{array}$ & $\begin{array}{c}-0.53 \\
(-0.52 \text { to }-0.54)\end{array}$ & $\begin{array}{c}-0.19 \\
(-0.20 \text { to }-0.18)\end{array}$ \\
\hline $\begin{array}{l}\text { Heavy damage } \\
(\phi)\end{array}$ & NA & NA & NA & $\begin{array}{c}0.03 \\
(0.02-0.11)\end{array}$ & $\begin{array}{c}0.42 \\
(0.32-0.43)\end{array}$ \\
\hline $\begin{array}{l}\text { Medium damage } \\
(\phi)\end{array}$ & NA & NA & NA & $\begin{array}{c}0.25 \\
(0.24-0.32)\end{array}$ & $\begin{array}{c}0.89 \\
(0.88-0.9)\end{array}$ \\
\hline $\begin{array}{l}\text { Heavy damage } \\
(\eta)\end{array}$ & NA & NA & NA & $\begin{array}{l}0.99 \\
(0-1)\end{array}$ & $\begin{array}{l}0.83 \\
(0-1)\end{array}$ \\
\hline $\begin{array}{l}\text { Medium damage } \\
(\eta)\end{array}$ & NA & NA & NA & $\begin{array}{c}0.92 \\
(0-1)\end{array}$ & $\begin{array}{c}0.33 \\
(0-1)\end{array}$ \\
\hline
\end{tabular}

Note: See Table 1 to match the six-letter codes to species names.

a fraction, $R$, of the specified initial maximum mapped radius $(20 \mathrm{~m})$. On average, growth of target species responded to neighbors within a distance of $13.78 \mathrm{~m}$ (Table 5). Effective neighborhood radii ranged from $3.2 \mathrm{~m}$ for Buchenavia tetraphylla to $19.84 \mathrm{~m}$ for $\mathrm{Cec}$ ropia schereberiana (Table 5).

The effects of distance between neighbors and target trees on NCI varied strikingly depending on the target tree species ( $\beta$ exponent; Table 5). For instance, the effects of neighbors on the growth of Dacryodes excelsa declined slightly less than linearly with distance to the neighbor $(\beta=0.86)$, while for Alchornea latifolia, the effects declined as roughly the square root of distance to neighbor $(\beta=0.50)$. Within the effective neighborhood of Buchenavia tetraphylla, there was very little decline in the effects of neighbors with distance $(\beta=0.09)$.

The exponent $\alpha$ in NCI controls the scaling of the effects of neighbor tree size on NCI, and hence on target tree growth. For Guarea guidonia, Manilkara bidentata, and Tabebuia heterophylla target trees, the exponent was close to two (Table 5), indicating that the competitive effects of neighbors were scaled to basal area of neighboring competitors (i.e., $\mathrm{dbh}^{2}$ ). For Casearia arborea, Cecropia schreberiana, Inga laurina, Schefflera morototoni, and Sloanea berteriana the competitive effects of neighbors were scaled as approximately a $3 / 2$ power of the dbh of the neighbor (i.e., $\alpha=1.5$ ). For Alchornea latifolia, larger neighboring trees had a disproportionately large effect on its growth $(\alpha=2.81)$.
Survival.-Probability of survival was predicted to respond to competitors within a smaller effective neighborhood radius (mean effective neighborhood radius $=11.85 \mathrm{~m}$ ) than growth. The range of effective neighborhood radii for the survival model ranged from $4.2 \mathrm{~m}$ for Sloanea berteriana to approximately $14 \mathrm{~m}$ for Cecropia schreberiana and Casearia arborea (Table 6).

For the survival model, the effects of distance between neighbors and target trees on NCI varied strikingly depending upon the target tree species ( $\beta$ exponent; Table 6). The effects of neighbors on the survival of Sloanea berteriana declined sharply with distance to neighbors $(\beta=2.76)$, while for the remainder of target species the decline was far more gradual.

The exponent $\alpha$ in NCI controls the scaling of the effects of neighbor tree size on NCI (and hence on target tree survival). For Cecropia schreberiana target trees, the exponent was slightly $>2$ (i.e., $\alpha=2.01$; Table 6), indicating that the competitive effects of neighbors on target survival were scaled to neighbor basal area (i.e., $\mathrm{dbh}^{2}$ ). For Buchenavia tetraphylla, $\mathrm{Ca}$ searia arborea, Manilkara bidentata, and Sloanea berteriana, $\alpha$ was considerably $>2$, indicating that a larger neighbor tree has a disproportionately bigger effect on the probability of survival of the target.

\section{Relative effects of crowding on tree growth and survival}

Growth.-The trees of each of the target species experienced a wide range of crowding conditions. Fig. 6 
TABle 5. Extended.

\begin{tabular}{|c|c|c|c|c|c|}
\hline GUAGUI & INGLAU & MANBID & SCHMOR & SLOBER & TABHET \\
\hline 539 & 897 & 1218 & 1888 & 2219 & 434 \\
\hline 7.53 & 9.94 & 8.06 & 8.66 & 4.15 & 2.55 \\
\hline$(7.45-7.75)$ & $(9.74-10.04)$ & $(7.76-8.09)$ & $(8.57-8.74)$ & $(4.12-4.32)$ & $(2.52-2.63)$ \\
\hline 4.85 & 3.79 & 2.81 & 9.61 & 0.90 & 3.15 \\
\hline$(4.52-4.91)$ & $(3.76-3.91)$ & $(2.78-2.95)$ & $(9.51-9.94)$ & $(0.85-0.91)$ & $(3.12-3.9)$ \\
\hline 1.07 & 1.20 & 1.01 & 2.64 & 1.02 & 1.66 \\
\hline$(1.06-1.11)$ & $(1.16-1.21)$ & $(1-1.02)$ & $(2.58-2.67)$ & $(1.01-0.12)$ & $(1.51-1.66)$ \\
\hline 15.2 & 13.0 & 14.8 & 19.8 & 9.9 & 5.4 \\
\hline$(14.9-15.26)$ & $(12.54-13.06)$ & $(14.6-14.9)$ & $(19.6-19.9)$ & $(9.8-10.1)$ & $(5.2-5.44)$ \\
\hline 2.10 & 1.25 & 2.18 & 1.19 & 1.38 & 2.10 \\
\hline$(2.08-2.23)$ & $(1.24-1.37)$ & $(2.07-2.20)$ & $(1.18-1.20)$ & $(1.37-1.52)$ & $(1.95-2.12)$ \\
\hline 0.27 & 0.23 & 0.50 & 0.62 & 0.19 & 0.0001 \\
\hline$(0-0.30)$ & $(0.22-0.29)$ & $(0.46-0.51)$ & $(0.55-0.63)$ & $(0.18-0.47)$ & $(0-0.0002)$ \\
\hline 20.61 & 193.17 & 198.14 & 6.38 & 124.47 & 193.9 \\
\hline$(17.72-20.81)$ & (191.24-200) & $(196.16-200)$ & $(6.31-6.63)$ & $(113.27-125.72)$ & $(191.96-195.84)$ \\
\hline 1.97 & 2.92 & 2.92 & 0.93 & 3.04 & 3.54 \\
\hline$(1.95-2.15)$ & $(2.89-2.95)$ & $(2.89-2.95)$ & $(0.92-0.97)$ & $(3.01-3.14)$ & $(3.44-3.58)$ \\
\hline-0.22 & -0.25 & -0.18 & -1.23 & 0.11 & 0.27 \\
\hline$(-0.25$ to -0.21$)$ & $(-0.26$ to -0.24$)$ & $(-0.17$ to -0.16$)$ & $(-1.24$ to -1.21$)$ & $(0.08-0.12)$ & $(0.26-0.39)$ \\
\hline 0.34 & 0.63 & 0.47 & NA & 0.38 & NA \\
\hline$(0.33-0.41)$ & $(0.33-0.64)$ & $(0.19-0.48)$ & & $(0.37-0.53)$ & \\
\hline 0.90 & 0.78 & 0.95 & NA & 0.74 & NA \\
\hline$(0.94-1)$ & $(0.77-0.79)$ & $(0.91-0.96)$ & & $(0.73-0.81)$ & \\
\hline 0.27 & 0.89 & 0.76 & NA & 0.87 & NA \\
\hline$(0-1)$ & $(0-1)$ & $(0.75-0.77)$ & & $(0.86-0.88)$ & \\
\hline 0.89 & 0.54 & 0.39 & NA & 0.94 & NA \\
\hline$(0-0.90)$ & $(0-1)$ & $(0.38-1)$ & & $(0.93-1)$ & \\
\hline
\end{tabular}

illustrates the decline in target growth across the range of actual neighborhood crowding conditions for each target species. This range is a function of the actual neighborhood composition of each target species at the LFDP, the estimated neighborhood radius, and the value of estimated parameters. The magnitudes of the $C$ and $D$ parameters (Table 5) provide an approximate measure of the amount of reduction in radial growth due to an incremental increase in crowding (NCI). The parameter $C$ determines the steepness of the decline in growth with an increase in NCI while $D$ determines the degree of crowding at which the decline becomes more marked. If $D$ is $\sim 1$, then growth declines as an exponential function of crowding. For species where the values of $D$ are $>1$ (e.g., Schefflera morototoni, Table 5) there is a "shoulder" to the function, where growth
FIG. 5. Predicted probability of survival as a function of target size using Eq. $2 \mathrm{~b}$ and parameters reported in Table 4. See Table 1 for scientific names of target species. Pioneer species are indicated with open symbols, secondary species with gray symbols, and late-successional species with solid symbols. Each species is plotted in its actual range of dbh values.

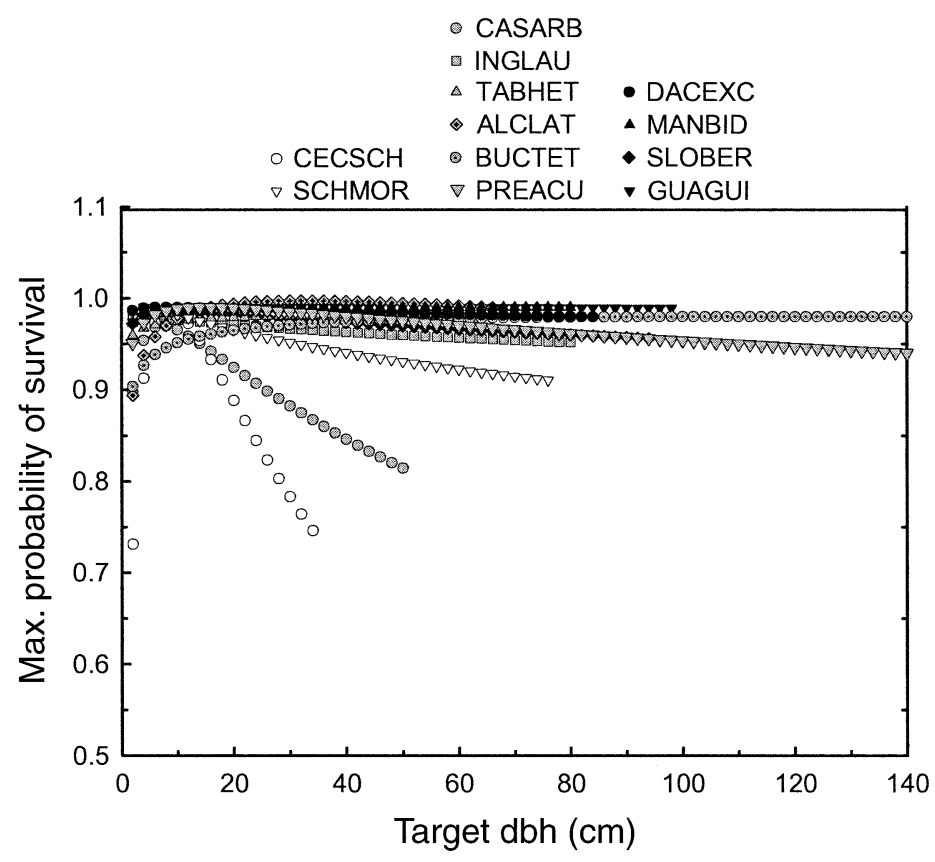


TABle 6. Parameter estimates and support intervals for the most likely survival models for 12 dominant trees.

\begin{tabular}{|c|c|c|c|c|}
\hline Parameter & ALCLAT & BUCTET & CASARB & $\mathrm{CECSCH}$ \\
\hline$n$ & 1145 & 375 & 5516 & 10313 \\
\hline Maximum probability & 0.99 & 0.99 & 0.97 & 0.99 \\
\hline survival & $(0.98-1)$ & $(0.98-1)$ & $(0.96-0.99)$ & $(0.97-1)$ \\
\hline C & 4.53 & 8.16 & 1.15 & 9.43 \\
\hline & $(4.35-4.57)$ & $(7.42-8.24)$ & $(1.14-1.29)$ & $(9.34-9.53)$ \\
\hline Radius (m) & $\begin{array}{c}(1.09-1.12) \\
6.67\end{array}$ & $\begin{array}{l}(3.01-3.42) \\
14.64\end{array}$ & $\begin{array}{c}(1.94-2.16) \\
14.58\end{array}$ & $\begin{array}{c}(2.22-2.26) \\
14.8\end{array}$ \\
\hline & $(6.6-6.75)$ & $(14.49-14.79)$ & $(14.4-14.95)$ & $(14.7-14.9)$ \\
\hline$\alpha$ & 1.56 & 2.62 & 2.94 & 2.01 \\
\hline$\beta$ & $\begin{array}{c}(1.55-1.59) \\
0.01\end{array}$ & $\begin{array}{c}(2.59-2.67) \\
0.43\end{array}$ & $\begin{array}{c}(2.83-2.97) \\
0.38\end{array}$ & $\begin{array}{c}(1.99-2.03) \\
0.38\end{array}$ \\
\hline & $(0.005-0.13)$ & $(0.42-0.46)$ & $(0-0.39)$ & $(0.37-0.39)$ \\
\hline$X_{0}(\mathrm{~cm})$ & $\begin{array}{c}32.21 \\
(28.34-32.53)\end{array}$ & $\begin{array}{c}119.7 \\
(102.9-120.9)\end{array}$ & $\begin{array}{c}7.26 \\
(7.19-7.34)\end{array}$ & $\begin{array}{c}8.45 \\
(8.37-8.54)\end{array}$ \\
\hline$X_{\mathrm{b}}$ & $\begin{array}{c}5.94 \\
(5.87-6.11)\end{array}$ & $\begin{array}{c}10.16 \\
(9.85-10.26)\end{array}$ & $\begin{array}{c}3.26 \\
(3.23-3.29)\end{array}$ & $\begin{array}{c}1.85 \\
(181-187)\end{array}$ \\
\hline $\operatorname{Gamma}(\gamma)$ & $\begin{array}{c}-1.94 \\
(-2 \text { to }-1.92)\end{array}$ & $\begin{array}{c}-1.97 \\
(-2 \text { to }-1.95)\end{array}$ & $\begin{array}{c}-1.77 \\
(-1.79 \text { to }-1.76)\end{array}$ & $\begin{array}{c}-1.99 \\
(-2 \text { to }-1.98)\end{array}$ \\
\hline Heavy damage $(\phi)$ & $\begin{array}{c}0.87 \\
(0.86-0.88)\end{array}$ & $\begin{array}{c}0.92 \\
(0.91-0.94)\end{array}$ & $\begin{array}{c}0.82 \\
(0.81-0.83)\end{array}$ & $\begin{array}{c}0.68 \\
(0.46-0.69)\end{array}$ \\
\hline Medium damage $(\phi)$ & $\begin{array}{c}0.97 \\
(0.96-0.98)\end{array}$ & $\begin{array}{c}0.99 \\
(0.98-1)\end{array}$ & $\begin{array}{c}0.97 \\
(0.96-0.99)\end{array}$ & $\begin{array}{c}0.98 \\
(0.96-1)\end{array}$ \\
\hline Heavy damage $(\eta)$ & $\begin{array}{c}0.19 \\
(0.18-0.192)\end{array}$ & $\begin{array}{c}0.99 \\
(0.98-1)\end{array}$ & $\begin{array}{c}0.65 \\
(0.64-0.66)\end{array}$ & $\begin{array}{c}0.52 \\
(0.51-0.53)\end{array}$ \\
\hline Medium damage $(\eta)$ & $\begin{array}{c}0.58 \\
(0.57-1)\end{array}$ & $\begin{array}{c}0.48 \\
(0.47-0.49)\end{array}$ & $\begin{array}{c}0.54 \\
(0-0.55)\end{array}$ & $\begin{array}{c}0.36 \\
(0.35-1)\end{array}$ \\
\hline
\end{tabular}

Note: See Table 1 to match the six-letter codes to species names.

initially declines slowly with increasing crowding, and then drops off exponentially. As crowding pressure (NCI) increased, the growth of the two pioneer tree species, Cecropia schreberiana and Schefflera morototoni, declined very steeply $(C=7.18$ and $C=9.61$, respectively; see Fig. 6). For the remainder of target species, the decline in growth with increasing crowding was less steep (Fig. 5). For two-thirds of species, negative estimated values for the coefficient $\gamma$ indicated that smaller trees were more sensitive to crowding than larger trees (Table 5). As expected, small trees of pioneer species were markedly susceptible to neighborhood crowding $(\gamma=-0.53$ and -1.23 , respectively, for Cecropia schreberiana and Schefflera morototoni). For the remaining one-third of target species, bigger trees were more sensitive to crowding.

Survival.-The magnitudes of the $C$ and $D$ parameters (Table 6) provide an approximate measure of the reduction in the probability of survival due to an incremental increase in crowding (NCI). Crowding had little effect on probability of survival for Sloanea berteriana (Fig. 7). For the remainder of target species, the decline in survival with increasing crowding was steep, particularly for pioneers such as Cecropia schereberiana and some secondary forest species such as Alchornea latifolia and Prestoea acuminata. Probability of survival was markedly lower for small target trees as indicated by the strongly negative values of $\gamma$, the parameter that determines susceptibility to crowding as a function of size (Table 6).
Effects of hurricane damage on growth and survival

Growth.-The effects of Hurricane Hugo damage on potential maximum growth rate of the target ( $\phi$ parameter) varied greatly depending both on the taxonomic identity of the target and the degree of damage. Trees heavily damaged by the hurricane grew $3-47 \%$ of their potential maximum, whereas trees that had only suffered medium damage (e.g., loss of large branches) grew $25-95 \%$ of their potential maximum (Table 5). Damage also altered the crowding effects of neighbors (parameter $\eta$ ). Damaged neighbors had much weaker effects on the growth of targets than undamaged competitors. For instance, heavily damaged neighbors of Guarea guidonia had only $27 \%$ of the crowding effect of a comparable healthy neighbor $(\eta=0.27)$, whereas neighbors that had suffered medium damage had $89 \%$ of the effect of a comparable healthy neighbor $(\eta=$ $0.89)$.

Survival.-The effect of previous hurricane damage on potential survival of the target ( $\phi$ parameter) was less marked than its effect on growth as estimated by the value of parameter $\phi$. Trees heavily damaged by the hurricane survived to $68-92 \%$ of their potential. Damage of medium severity did not, in fact, alter maximum probability of survival (i.e., support intervals for $\phi$ contained 1.0) for most species (Table 6). Nevertheless, damage altered the crowding effects of neighbors (parameter $\eta$ ) on target survival. In general, damaged neighbors had significantly weaker effects on the survival of targets than undamaged neighbors. 
TABLE 6. Extended.

\begin{tabular}{cccc}
\hline \hline DACEXC & GUAGUI & INGLAU & MANBID \\
\hline 1504 & 1036 & 1418 & 1538 \\
0.99 & 0.99 & 0.98 & 0.99 \\
$(0.98-1)$ & $(0.98-1)$ & $(0.97-0.99)$ & $0.98-1)$ \\
0.22 & 2.36 & $(0.26-0.31)$ & 0.37 \\
$(0.2-0.23)$ & $(2.22-2.39)$ & 1.18 & $(0.36-0.42)$ \\
1.31 & 2.01 & $(1.17-1.36)$ & $(1.57-2.12)$ \\
$(1-.133)$ & $(1.98-2.03)$ & 13.69 & 12.6 \\
10.81 & 12.58 & $(13.5-14.11)$ & $(12.3-14.4)$ \\
$(9.45-14.1)$ & $(12.46-12.7)$ & 1.29 & 3.05 \\
0.68 & 0.84 & $(0.85-1.3)$ & $(3.02-3.93)$ \\
$(0.67-0.7)$ & $(0.83-0.85)$ & 0.14 & 1.04 \\
0.86 & 0.05 & $(0-0.15)$ & $(0.45-1.05)$ \\
$(0.85-0.89)$ & $(0-0.04)$ & 3.54 & 81.91 \\
7.71 & 43.19 & $(2.94-3.58)$ & $(81.1-97.8)$ \\
$(7.62-8.47)$ & $(36.28-43.62)$ & 12.87 & 19.6 \\
16.47 & 17.07 & $(12.49-13.01)$ & $(18.03-19.79)$ \\
$(16.30-18.4)$ & $(16.9-20)$ & -1.99 & -1.69 \\
-1.92 & -1.29 & $(-2$ to -1.97$)$ & $(-2$ to -1.59$)$ \\
$(-2$ to -1.9$)$ & 0.72 & 0.92 \\
0.84 & 0.95 & $(0.68-0.73)$ & $(0.91-0.93)$ \\
$(0.83-0.88)$ & $(0.92-0.96)$ & 0.99 & 0.99 \\
0.99 & 0.99 & $(0.98-1)$ & $(0.98-1)$ \\
$(0.98-1)$ & $(0.98-1)$ & 0.72 & 0.83 \\
0.40 & 0.08 & $(0-1)$ & $(0-1)$ \\
$(0.39-0.41)$ & $(0-1)$ & 0.16 & 0.01 \\
0.03 & 0.25 & $(0.17-1)$ & $(0-0.02)$ \\
$(0.02-0.04)$ & $(0-1)$ & &
\end{tabular}

For instance, a neighbor of Dacryodes excelsa that had received medium damage had, on average, only $3 \%$ of the effect of a comparable undamaged neighbor.

\section{The nature of competitive coefficients}

Growth.-Our analyses indicate striking variation in the effects of crowding (as measured by $\lambda_{\mathrm{s}}$, our speciesspecific competition index), depending on both the identity of the target tree and neighbors (Table 7). For all 11 species for which the growth model was estimated, a simplified model that ignored differences in the identities of neighboring species (i.e., estimated a single $\lambda$ regardless of species of neighbor) had a significantly lower likelihood than the model that estimated separate $\lambda$ values for each species of neighbor ( $P$ values for likelihood ratio test values for comparisons of "full" vs. "equivalent competitor" models were all $<0.05$ ). For all of the target species, the most
FIG. 6. Predicted decline in growth as a function of Neighborhood Competiton Index $(\mathrm{NCI})$ using Eq. 4 and parameters reported in Table 4. See Table 1 for scientific names of target species. Pioneer species are indicated with open symbols, secondary species with gray symbols, and late-successional species with solid symbols.

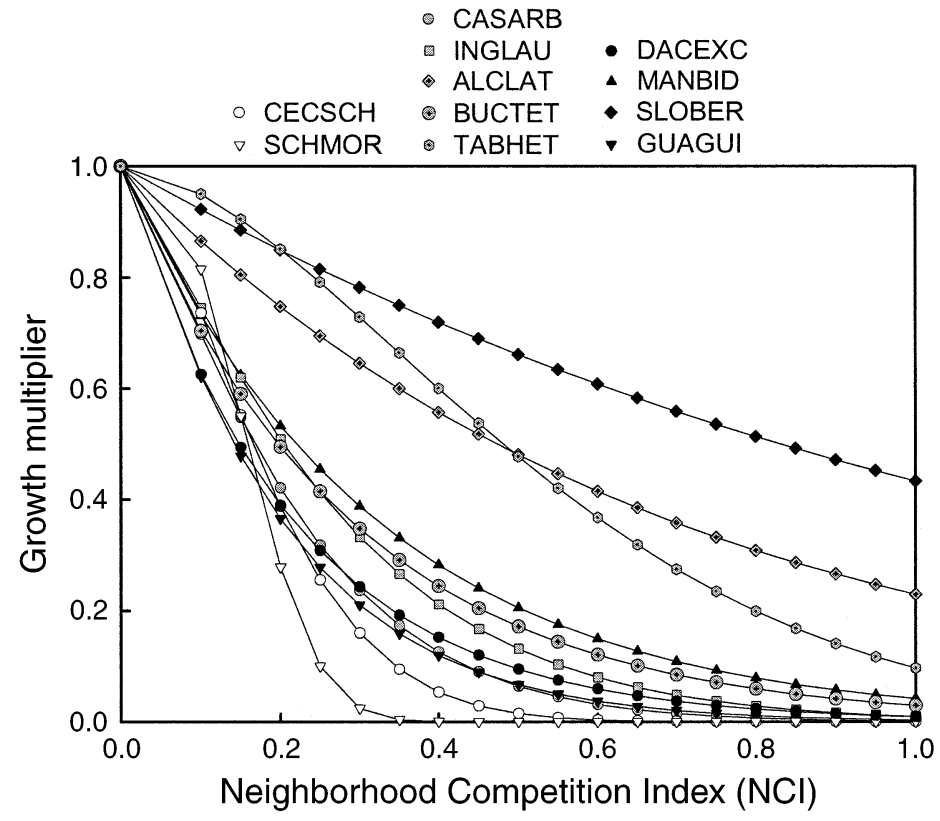


TABle 6. Extended.

\begin{tabular}{|c|c|c|c|c|}
\hline Parameter & PREMON & SCHMOR & SLOBER & TABHET \\
\hline$n$ & 7780 & 4254 & 3121 & 718 \\
\hline Maximum probability & 0.99 & 0.99 & 0.98 & 0.98 \\
\hline survival & $(0.98-1)$ & $(0.98-1)$ & $(0.97-1)$ & $(0.97-1)$ \\
\hline C & 0.46 & 1.66 & 0.006 & 0.26 \\
\hline & $(0.45-0.48)$ & $(1.64-1.74)$ & $(0-0.007)$ & $(0.21-0.27)$ \\
\hline$D$ & $\begin{array}{c}1.86 \\
(15-188)\end{array}$ & $\begin{array}{c}1.2 \\
(17-122)\end{array}$ & 2.86 & 4.74 \\
\hline Radius (m) & 12.45 & 11.1 & $\begin{array}{c}(2.83-5) \\
4.2\end{array}$ & 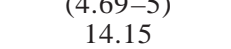 \\
\hline & $(12.15-12.61)$ & $(10.95-11.4)$ & $(2.7-4.35)$ & $(13.95-14.55)$ \\
\hline$\alpha$ & 0.01 & 1.10 & 2.61 & 1.24 \\
\hline$\beta$ & $\begin{array}{c}(0-0.02) \\
0.44\end{array}$ & $\begin{array}{c}(1.08-1.19) \\
0.19\end{array}$ & $\begin{array}{c}(0-4) \\
2.76\end{array}$ & $\begin{array}{l}(1.03-1.25) \\
0.25\end{array}$ \\
\hline & $(0.34-0.45)$ & $(0-0.20)$ & $(1.13-4)$ & $(0-0.25)$ \\
\hline$X_{0}(\mathrm{~cm})$ & $\begin{array}{c}14.7 \\
(12.49-14.85)\end{array}$ & $\begin{array}{c}3.93 \\
(3.89-4.05)\end{array}$ & $\begin{array}{c}9.29 \\
(9.1-9.38)\end{array}$ & $\begin{array}{c}99.66 \\
(42.85-100.66)\end{array}$ \\
\hline$X_{\mathrm{b}}$ & $\begin{array}{c}7.01 \\
(5.18-7.07)\end{array}$ & $\begin{array}{c}7.24 \\
(6.87-7.31)\end{array}$ & $\begin{array}{c}9.49 \\
(9.4-9.59)\end{array}$ & $\begin{array}{c}17.78 \\
(17.6-20)\end{array}$ \\
\hline $\operatorname{Gamma}(\gamma)$ & $\begin{array}{c}-0.75 \\
(-0.76 \text { to }-0.72)\end{array}$ & $\begin{array}{c}-1.93 \\
(-1.95 \text { to }-1.89)\end{array}$ & $\begin{array}{c}-0.19 \\
(-2 \text { to }-0.18)\end{array}$ & $\begin{array}{c}-0.92 \\
(-0.93 \text { to }-0.91)\end{array}$ \\
\hline Heavy damage $(\phi)$ & $\begin{array}{c}0.57 \\
(0.51-0.58)\end{array}$ & $\begin{array}{c}0.68 \\
(0.67-0.69)\end{array}$ & $\begin{array}{c}0.92 \\
(0.91-0.93)\end{array}$ & $\begin{array}{c}0.70 \\
(0.69-0.74)\end{array}$ \\
\hline Medium damage $(\phi)$ & $\begin{array}{l}0.53 \\
(0-1)\end{array}$ & $\begin{array}{c}0.99 \\
(0.98-1)\end{array}$ & $\begin{array}{c}0.99 \\
(0.98-1)\end{array}$ & $\begin{array}{c}0.99 \\
(0.98-1)\end{array}$ \\
\hline Heavy damage $(\eta)$ & $\begin{array}{l}0.07 \\
(0-1)\end{array}$ & $\begin{array}{c}0.64 \\
(0.63-0.65)\end{array}$ & $\begin{array}{l}0.29 \\
(0-1)\end{array}$ & $\begin{array}{c}0.99 \\
(0.98-1)\end{array}$ \\
\hline Medium damage $(\eta)$ & $\begin{array}{l}0.69 \\
(0-1)\end{array}$ & $\begin{array}{l}0.17 \\
(0.91-1)\end{array}$ & $\begin{array}{c}0.72 \\
(0-1)\end{array}$ & $\begin{array}{l}0.91 \\
(0-1)\end{array}$ \\
\hline
\end{tabular}

parsimonious model distinguished conspecific competitors and included three or four functional groupings of neighboring heterospecific competitors (Table 3). These functional groupings were idiosyncratic for each target species (Table 7).

Survival.-Species-specific variation in the effects of crowding (as measured by $\lambda_{\mathrm{s}}$, our species-specific competition index) on survival was also high (Table
8). With the exception of Dacryodes excelsa, Manilkara bidentata, Inga laurina, Sloanea berteriana, and Tabebuia heterophylla, a simplified model that ignored differences in the identities of neighboring species (i.e., estimated a single $\lambda$ regardless of species of neighbor) had lower likelihood than the model that estimated separate $\lambda$ values for each species of neighbor (Table 4). For Alchornea latifolia, an alternate

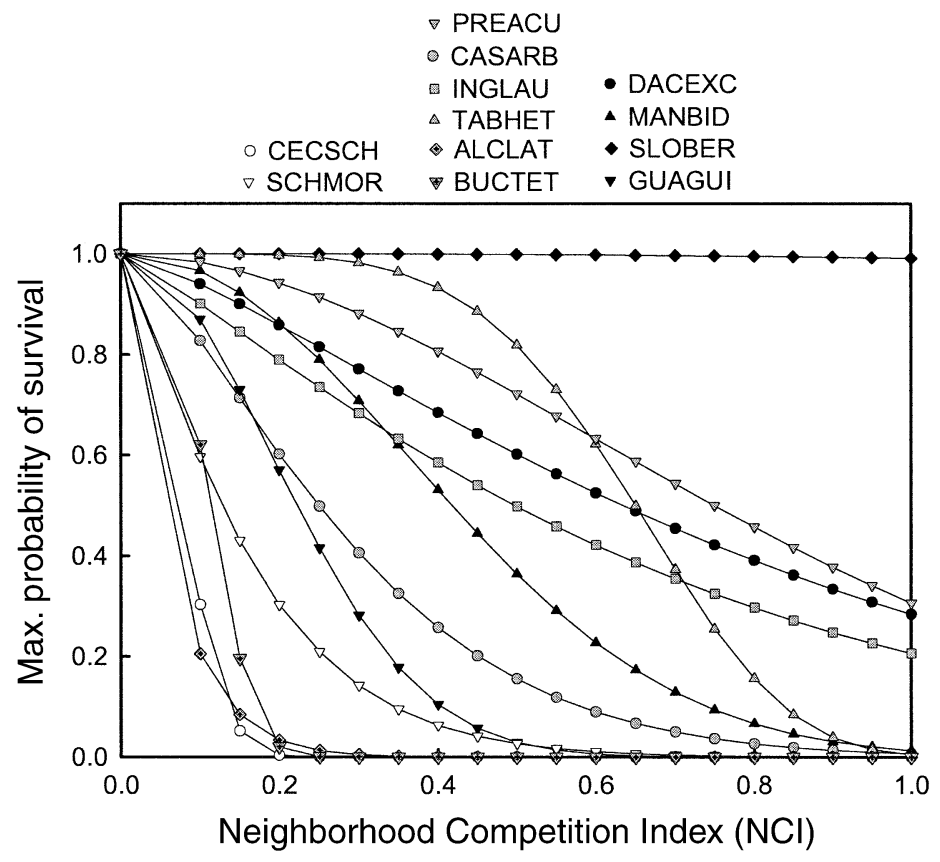

FIG. 7. Predicted decline in survival as a function of Neighborhood Competition Index (NCI) using Eq. 4 and parameters reported in Table 4. See Table 1 for scientific names of target species. Pioneer species are indicated with open symbols, secondary species with gray symbols, and late-successional species with solid symbols. 
model that simply differentiated between conspecific and heterospecific competitors was the most parsimonious (Table 4). For Buchenavia tetraphylla, Casearia arborea, Cecropia schreberiana, Guarea guidonia, Prestoea acuminata, and Schefflera morototoni, the most parsimonious model included four to five functional groupings of neighboring heterospecific competitors (Table 4 and 6).

\section{Magnitude of neighborhood effects on growth and survival}

To illustrate the magnitude of neighborhood effects on growth and survival, we used estimated parameters for the most parsimonious model for one of the target species to calculate the decline in growth and survival from a standardized neighborhood around a $5-\mathrm{cm} \mathrm{dbh}$ target sapling. For instance, maximum annual growth for a 5-cm Cecropia schreberiana tree was estimated at $23.4 \mathrm{~mm} / \mathrm{yr}$ (Table 3 ). A 5 -cm sapling of this same species growing at a distance of $5 \mathrm{~m}$ from a $10-\mathrm{cm}$ conspecific neighbor is expected to grow only 20.59 mm/yr (Fig. 8). An identical Alchornea latifolia neighbor at the same distance will only decrease the growth of this tree to $22.57 \mathrm{~mm} / \mathrm{yr}$ (Fig. 8).

\section{Discussion}

Our likelihood method shows great potential for modeling tree growth and survival in tropical forests. The goodness of fit of the growth model $\left(R^{2}\right)$ is comparable to that obtained in other tropical forests (Vanclay 1991, Chai and LeMay 1993, Moravie et al. 1999, Gourlet-Fleury and Houllier 2000). The fit of the mortality model was also quite good, particularly for lightdemanding species. The added benefits of our method are that (1) it can be applied to all stems in uneven aged stands, while previous efforts used only adult trees or data from stands with uniform size distributions; (2) it disentangles the effects of crowding and size on tree growth and mortality; and (3) it provides robust estimates for the value of per capita competitive coefficients $(\lambda s)$ for individual species. The method is also sufficiently general to apply to a broad range of forests and only requires repeated census data. Suitable data for tropical forests are becoming available through a recently established network of permanent forest plots throughout the tropics (Condit 1998).

\section{Size effects}

Growth.-Species at the Luquillo Forest Dynamics Plot (LFDP) display great variation in size-dependent growth. As expected, pioneers displayed highest growth at smaller size categories. Three other species, Alchornea latifolia, Casearia arborea, and Dacryodes excelsa also showed highest growth in small size classes. In the continuum from pioneer to shade-tolerant life histories, Alchornea latifolia and Casearia arborea can be classified as "non-pioneer light demanding species (Swaine and Whitmore 1988). These are species that can establish successfully in the shade but grow best at relatively high light levels. The third species, D. excelsa, is a mature forest species that can germinate and persist in the shade but has the potential to grow fast under favorable conditions (e.g., when they reach the canopy or in temporary canopy gaps; cf., Canham 1988). These results lend support to the notion that tropical tree life histories may not obey simplistic tradeoffs between shade tolerance and the ability to grow in full sun but rather display complex ontogenies in response to gradients in light availability (Swaine and Whitmore 1988, Clark and Clark 1992, Wyckoff and Clark 2002).

Survival.-There is scarce empirical or theoretical support to justify a particular functional form for the shape of the relationship between size and survival. In general, empirical studies suggest that the high mortality rates found in small diameter size classes decrease as trees get larger and develop structural support and acquire reserves to withstand environmental stresses (Lieberman et al. 1985, Clark and Clark 1992, Condit et al. 1995, Blundell and Peart 2001). Unfortunately, it is impossible to determine from available data on juvenile mortality whether higher mortality rates in small size classes are a result of greater crowding in these size classes (e.g., dense regeneration in gaps) or some inherent cost of being small (e.g., absence of physiological buffering capacity).

To overcome these potential difficulties, we used an approach that allowed us to estimate the mean potential survival of trees of each of the target species as a function of variation in diameter, in the absence of crowding (Fig. 5). In general, mortality was higher at smaller size classes but the relationship was quite flat for the majority of target species. Although the model that included only size effects was, for the most part, not supported, the estimated values of $\gamma$ for the survival model suggest that greater mortality in small size classes is driven in large part by greater susceptibility to crowding in small trees. Our results also suggest that size-dependent susceptibility to crowding is important but not sufficient to account for mortality of some species at the LFDP. The two pioneer species, Cecropia schreberiana and Schefflera morototoni, and some of the light-demanding secondary-successional species, such as Casearia arborea, have high growth and respiration rates (Silander 1979) and may be less able to withstand unfavorable resource conditions, structural damage, or tissue losses to pathogens, even in the absence of competitors (Kobe 1999). In contrast, mature forest species such as Manilkara bidentata show little change in mortality across a range of size classes. There is some empirical evidence that mature-phase, shade tolerant species suffer low juvenile mortality perhaps as a consequence of lower maintenance costs (Clark and Clark 1992, Condit et al. 1995, Kobe 1999). 
TABLE 7. Estimated competitive coefficients (lambdas) with support intervals for the most common target species in growth model.

\begin{tabular}{|c|c|c|c|c|c|}
\hline \multirow[b]{2}{*}{ Species } & \multicolumn{5}{|c|}{ Competitive coefficients } \\
\hline & ALCLAT & BUCTET & CASARB & $\mathrm{CECSCH}$ & DACEXC \\
\hline Alchomea latifolia & $\begin{array}{c}0.05 \\
(0-0.06)\end{array}$ & $\begin{array}{c}0.0001 \mathrm{a} \\
(0-0.0003)\end{array}$ & $\begin{array}{c}0.003 \mathrm{a} \\
(0-0.003)\end{array}$ & $\begin{array}{c}0.71 \mathrm{c} \\
(0.69-0.72)\end{array}$ & $\begin{array}{c}0.08 \mathrm{~b} \\
(0.05-0.09)\end{array}$ \\
\hline Bucchenavia tetraphylla & $\begin{array}{c}0.10 \mathrm{a} \\
(0.08-0.11)\end{array}$ & $\begin{array}{c}0.0001 \\
(0-0.0002)\end{array}$ & $\begin{array}{c}0.51 \mathrm{~b} \\
(0.50-0.53)\end{array}$ & $\begin{array}{c}1 \mathrm{~d} \\
(0.99-1)\end{array}$ & $\begin{array}{c}0.01 \mathrm{a} \\
(0-0.02)\end{array}$ \\
\hline Casearia arborea & $\begin{array}{c}0.62 \mathrm{~b} \\
(0.61-0.67)\end{array}$ & $\begin{array}{c}0.63 \mathrm{~d} \\
(0.49-0.64)\end{array}$ & $\begin{array}{c}0.96 \\
(0.94-0.97)\end{array}$ & d & $\mathrm{b}$ \\
\hline Cecropia schreberiana & $\begin{array}{c}1 \mathrm{~d} \\
(0.99-1)\end{array}$ & $\begin{array}{c}0.30 \mathrm{c} \\
(0.29-0.31)\end{array}$ & $\mathrm{a}$ & $\begin{array}{c}0.62 \\
(0.61-0.63)\end{array}$ & $\mathrm{a}$ \\
\hline Dacryodes excelsa & $\begin{array}{c}0.45 \mathrm{c} \\
(0.44-0.46)\end{array}$ & $\mathrm{a}$ & $\begin{array}{c}0.55 \mathrm{c} \\
(0.53-0.56)\end{array}$ & $\begin{array}{c}0.33 \mathrm{~b} \\
(0.32-0.34)\end{array}$ & $\begin{array}{c}1 \\
(0.99-1)\end{array}$ \\
\hline Guarea guidonia & $\mathrm{c}$ & d & $\begin{array}{c}1 \mathrm{~d} \\
(0.85-1)\end{array}$ & $\mathrm{c}$ & $\begin{array}{c}0.52 \mathrm{c} \\
(0.51-0.53)\end{array}$ \\
\hline Inga laurina & $\mathrm{a}$ & $\mathrm{c}$ & a & $\begin{array}{c}0.02 \mathrm{a} \\
(0-0.03)\end{array}$ & $\mathrm{c}$ \\
\hline Manilkara bidentata & $\mathrm{b}$ & $\mathrm{a}$ & d & $\mathrm{d}$ & $\begin{array}{c}0.89 \mathrm{~d} \\
(0.88-0.91)\end{array}$ \\
\hline Prestoea acuminata & a & $\mathrm{a}$ & $\mathrm{c}$ & d & $\mathrm{b}$ \\
\hline Psychotria berteriana & d & $\mathrm{d}$ & $\mathrm{a}$ & $\mathrm{b}$ & $\mathrm{b}$ \\
\hline Schefflera morototoni & d & $\mathrm{c}$ & $\mathrm{a}$ & $\mathrm{a}$ & $\mathrm{c}$ \\
\hline Sloanea berteriana & $\mathrm{b}$ & $\begin{array}{c}0.16 \mathrm{~b} \\
(0.15-0.17)\end{array}$ & d & $\mathrm{c}$ & $\mathrm{c}$ \\
\hline Tabebuia heterophylla & $\mathrm{b}$ & d & $\mathrm{c}$ & $\mathrm{c}$ & a \\
\hline Rare species & $\mathrm{b}$ & $\mathrm{b}$ & $\mathrm{c}$ & $\mathrm{d}$ & $\mathrm{d}$ \\
\hline Species group 1 & a & $\mathrm{a}$ & b & $\mathrm{b}$ & $\mathrm{a}$ \\
\hline Species group 2 & d & $\mathrm{c}$ & d & $\mathrm{b}$ & d \\
\hline Species group 3 & $\mathrm{~b}$ & $\mathrm{~d}$ & $\mathrm{a}$ & $\mathrm{c}$ & $\mathrm{c}$ \\
\hline Species group 4 & $\mathrm{a}$ & $\mathrm{b}$ & a & $\mathrm{b}$ & $\mathrm{d}$ \\
\hline Species group 5 & $\mathrm{a}$ & $\mathrm{d}$ & c & b & c \\
\hline
\end{tabular}

Notes: Identical letters indicate that species had an identical effect on the target in the most likely model. Intraspecific coefficients are indicated in italics.

\section{Neighborhood scale competition}

Crowding effects on growth and survival appear to be idiosyncratic to each individual species and, with the exception of pioneers, there is little commonality among species that share similar life histories (Figs. 6, 7). Neighborhood effects on tree survival were more predictable than on growth as reflected by the ability of the model to explain individual tree responses to crowding, particularly for light-demanding species (Fig. 3). The LFDP has a higher density of small diameter trees than most other tropical forests, probably due to disturbance-driven regeneration (Thompson et al. 2002). Intense competitive thinning of densely packed saplings and/or sprouts that grew after hurricane damage could have facilitated our ability to detect crowding effects on mortality (Vandermeer et al. 2001). The effects of neighborhood competition on mortality may be less tractable in mature tropical forests with little natural disturbance where typical annual rates of mortality are 1-2\% of stems (Phillips and Gentry 1994, Condit et al. 1995). In these forests, density effects may operate primarily at the seedling stage and competitive thinning may play a secondary role to microsite variation in resource availability or vulnerability to pests and pathogens (e.g., Janzen-Connell effects).

\section{Hurricane effects}

Tree species in the LFDP differ strikingly in both their susceptibility to hurricane disturbance (Fig. 1; Zimmerman et al. 1994) and the nature of their recovery from wind disturbance, at both the individual plant level (through repair of damage) and the population level through reproduction, seedling establishment, and juvenile response to enhanced resource availability (e.g., Walker 1991, You and Petty 1991, Boucher et al. 1994, Zimmerman et al. 1994, Cooper-Ellis et al. 1999; C. D. Canham, J. Thompson and J. K. Zimmerman, unpublished data). Tradeoffs between species susceptibility to hurricanes and their ability to exploit increased light availability (Zimmerman et al. 1994: Fig. 1) suggest that these traits should be considered as part of a suite of life history traits that determine patterns of relative abundance and succession in forest recovery from hurricane damage.

Ultimately, the effects that these differential responses to hurricane disturbance have on forest dynamics 
TABle 7. Extended.

\begin{tabular}{|c|c|c|c|c|c|}
\hline \multicolumn{6}{|c|}{ Competitive coefficients } \\
\hline GUAGUI & INGLAU & MANBID & SCHMOR & SLOBER & TABHET \\
\hline $\begin{array}{c}0.68 \mathrm{~b} \\
(0.54-0.69)\end{array}$ & $\begin{array}{c}0.006 \mathrm{a} \\
(0-0.007)\end{array}$ & $\begin{array}{c}0.06 \mathrm{a} \\
(0.002-0.07)\end{array}$ & $\begin{array}{c}0.003 \mathrm{a} \\
(0-0.004)\end{array}$ & $\begin{array}{c}0.12 \mathrm{~b} \\
(0.03-0.13)\end{array}$ & $\begin{array}{c}0.24 \\
(0.23-0.25)\end{array}$ \\
\hline $\begin{array}{c}0.63 \mathrm{c} \\
(0.62-0.77)\end{array}$ & $\begin{array}{c}0.34 \mathrm{~d} \\
(0.33-0.36)\end{array}$ & $\mathrm{a}$ & $\begin{array}{c}0.18 \mathrm{c} \\
(0.17-0.19)\end{array}$ & $\begin{array}{c}0.001 \mathrm{a} \\
(0-0.002)\end{array}$ & $\begin{array}{l}0.02 \mathrm{c} \\
(0-0.01)\end{array}$ \\
\hline $\mathrm{b}$ & $\mathrm{d}$ & $\mathrm{a}$ & $\begin{array}{c}0.36 \mathrm{~d} \\
(0.35-0.37)\end{array}$ & $\mathrm{b}$ & $\mathrm{a}$ \\
\hline $\begin{array}{c}0.06 \mathrm{a} \\
(0.01-0.07)\end{array}$ & $\mathrm{a}$ & $\begin{array}{c}0.33 \mathrm{c} \\
(0.32-0.38)\end{array}$ & $\mathrm{a}$ & $\mathrm{a}$ & $\begin{array}{c}0.72 \\
(0.54-0.72)\end{array}$ \\
\hline $\begin{array}{c}1 \mathrm{~d} \\
(0.96-1)\end{array}$ & $\begin{array}{c}1 \mathrm{e} \\
(0.99-1)\end{array}$ & $\begin{array}{c}0.77 \mathrm{~d} \\
(0.74-0.78)\end{array}$ & $\mathrm{a}$ & $\begin{array}{c}0.77 \mathrm{c} \\
(0.76-0.88)\end{array}$ & d \\
\hline $\begin{array}{c}0.06 \\
(0.05-0.065)\end{array}$ & $\begin{array}{c}0.17 \mathrm{c} \\
(0.12-0.18)\end{array}$ & $\mathrm{c}$ & d & $\mathrm{c}$ & $\mathrm{c}$ \\
\hline$b$ & $\begin{array}{c}0.93 \\
(0.89-0.94)\end{array}$ & $\mathrm{a}$ & $\begin{array}{c}0.0004 \mathrm{~b} \\
(0-0.0005)\end{array}$ & $\begin{array}{c}1 \mathrm{~d} \\
(0.88-1)\end{array}$ & $\mathrm{c}$ \\
\hline d & $\mathrm{d}$ & $\begin{array}{c}1 \\
(0.93-1)\end{array}$ & $\mathrm{c}$ & $\mathrm{d}$ & d \\
\hline $\mathrm{a}$ & $\begin{array}{c}0.13 \mathrm{~b} \\
(0.12-0.14)\end{array}$ & $\begin{array}{c}0.01 \mathrm{~b} \\
(0-0.02)\end{array}$ & d & b & $\mathrm{a}$ \\
\hline $\mathrm{c}$ & $\mathrm{c}$ & $\mathrm{c}$ & $\mathrm{a}$ & $\mathrm{a}$ & d \\
\hline d & $\mathrm{b}$ & b & $\begin{array}{c}1 \\
(0.99-1)\end{array}$ & b & a \\
\hline $\mathrm{a}$ & a & $\mathrm{a}$ & $\mathrm{d}$ & $\begin{array}{c}0.36 \\
(0.35-0.53)\end{array}$ & $\begin{array}{c}1 \mathrm{~b} \\
(0.99-1)\end{array}$ \\
\hline d & $\mathrm{e}$ & $\mathrm{b}$ & d & a & $\begin{array}{c}0.11 \\
(0.10-0.17)\end{array}$ \\
\hline $\mathrm{a}$ & $\mathrm{d}$ & $\mathrm{c}$ & $\mathrm{a}$ & b & $\mathrm{d}$ \\
\hline $\mathrm{b}$ & $\mathrm{d}$ & $\mathrm{b}$ & $\mathrm{a}$ & $\mathrm{b}$ & $\mathrm{d}$ \\
\hline $\mathrm{b}$ & $\mathrm{e}$ & $\begin{array}{c}0.89 \mathrm{e} \\
(0.88-1)\end{array}$ & $\mathrm{b}$ & d & d \\
\hline $\mathrm{a}$ & $\mathrm{b}$ & $\mathrm{e}$ & $\mathrm{b}$ & $\mathrm{b}$ & $\mathrm{b}$ \\
\hline $\mathrm{a}$ & $\mathrm{a}$ & $\mathrm{e}$ & $\mathrm{a}$ & $\mathrm{d}$ & $\mathrm{a}$ \\
\hline $\mathrm{a}$ & $\mathrm{d}$ & $\mathrm{c}$ & $\mathrm{a}$ & b & b \\
\hline
\end{tabular}

are played out at a neighborhood scale. Differential adult susceptibility to damage determines the location and size of canopy gaps (Fig. 1; Canham et al. 2004), and differential response to crowding in these gaps determines the trajectory of recovery after hurricane disturbance (see Discussion: Neighborhood scale competition; Zimmerman et al. 1994). Our model clearly demonstrates that tree growth and mortality in gaps depends on: (1) abundance and taxonomic identity of trees in the neighborhood (Figs. 6, 7), (2) growth strategies of trees colonizing gaps (Figs. 4, 5), (3) differential ability of adult trees to recover from damage (parameter $\phi$ on Tables 5 and 6), and (4) ability of target species to take advantage of competitive release resulting from damage to neighboring adults (parameter $\eta$ on Tables 5 and 6 ). Our results illustrate a large degree of species-specific variation in the effects of crowding and previous hurricane damage on growth and survival (Tables 5, 6, Figs. 6, 7).

Growth.-The effects of previous damage on standing adult trees (parameter $\phi$ ) had little effect on subsequent growth of Schefflera morototoni and secondary forest species but were important in explaining tree growth of Cecropia schreberiana and late-successional species (Tables 3,4). Assessment of hurricane damage for the LFDP was limited to adult trees. Diameter dis- tributions show that the majority of stems for pioneer and secondary forest species were in small size classes. Thus, the majority of stems for these species were not scored for damage. In contrast, the initial census of late-successional species included a large number of adults that had been scored for damage. The exception to this rule was the pioneer Cecropia schreberiana. The extremely low values for parameter $\phi$ (Table 6) that estimate the effects of previous damage on growth of this target species suggest that the low density of wood for this species makes it particularly susceptible to damage and this damage has dramatic effects on subsequent growth.

The absence of an effect of previous damage to neighbors on growth (parameter $\eta$ ) for most pioneers and secondary target species may reflect the complex land use history of the LFDP and its interaction with hurricane disturbance. The northern two-thirds of the LFDP were logged and farmed at the beginning of the last century and, as a result, they contain most of the secondary forest species, while the southern third was relatively undisturbed and contains primarily late-successional species (Thompson et al. 2002). Secondary species are, in general, more susceptible to hurricane damage than late-successional species, and thus Hurricane Hugo reinforced the dominant effect of land use 
TABLE 8. Estimated competitive coefficients with support intervals for the most common target species in the mortality model.

\begin{tabular}{|c|c|c|c|c|c|}
\hline \multirow[b]{2}{*}{ Species } & \multicolumn{5}{|c|}{ Competitive coefficients } \\
\hline & ALCLAT & BUCCAP & CASARB & $\mathrm{CECSCH}$ & DACEXC \\
\hline Alchomea latifolia & $\begin{array}{c}1 \\
(0.99-1)\end{array}$ & $\begin{array}{c}0.02 \mathrm{a} \\
(0-0.03)\end{array}$ & $\begin{array}{c}0.05 \mathrm{a} \\
(0-0.06)\end{array}$ & $\begin{array}{c}0.17 \mathrm{~b} \\
(0.16-0.18)\end{array}$ & NA \\
\hline Bucchenavia tetraphylla & $\begin{array}{c}0.044 \mathrm{~b} \\
(0.041-0.045)\end{array}$ & $\begin{array}{c}0.37 \\
(0.36-0.39)\end{array}$ & $\begin{array}{c}0.0001 \mathrm{~b} \\
(0-0.0002)\end{array}$ & b & NA \\
\hline Casearia arborea & b & $\begin{array}{c}0.09 \mathrm{~b} \\
(0-0.10)\end{array}$ & $\begin{array}{c}1 \\
(0.95-1)\end{array}$ & $\begin{array}{c}1 \mathrm{e} \\
(0.99-1)\end{array}$ & NA \\
\hline Cecropia schreberiana & $\mathrm{b}$ & $\mathrm{b}$ & $\mathrm{a}$ & $\begin{array}{c}0.75 \\
(0.74-0.77)\end{array}$ & NA \\
\hline Dacryodes excelsa & $\mathrm{b}$ & $\begin{array}{c}0.68 \mathrm{c} \\
(0.39-0.69)\end{array}$ & $\mathrm{b}$ & $\begin{array}{c}0.03 \mathrm{a} \\
(0.02-0.04)\end{array}$ & NA \\
\hline Guarea guidonia & $\mathrm{b}$ & a & $\begin{array}{c}0.05 \mathrm{~d} \\
(0.04-0.06)\end{array}$ & $\begin{array}{c}0.28 \mathrm{c} \\
(0.27-0.29)\end{array}$ & NA \\
\hline Inga laurina & $\mathrm{b}$ & $\begin{array}{c}1 \mathrm{~d} \\
(0.99-1)\end{array}$ & d & $\mathrm{a}$ & NA \\
\hline Manilkara bidentata & $\mathrm{b}$ & $\mathrm{d}$ & $\mathrm{b}$ & $\mathrm{b}$ & NA \\
\hline Prestoea acuminata & b & $\mathrm{b}$ & $\begin{array}{c}0.07 \mathrm{c} \\
(0.06-0.08)\end{array}$ & $\begin{array}{c}0.59 \mathrm{~d} \\
(0.58-0.61)\end{array}$ & NA \\
\hline Psychotria berteriana & $\mathrm{b}$ & d & d & $\mathrm{e}$ & NA \\
\hline Schefflera morototoni & $\mathrm{b}$ & $\mathrm{c}$ & d & d & NA \\
\hline Sloanea berteriana & b & $\mathrm{c}$ & $\mathrm{c}$ & $\mathrm{c}$ & NA \\
\hline Tabebuia heterophylla & b & $\mathrm{a}$ & a & $\mathrm{a}$ & NA \\
\hline Rare species & b & $\mathrm{a}$ & c & b & NA \\
\hline Species group 1 & $\mathrm{~b}$ & $\mathrm{c}$ & $\mathrm{b}$ & a & NA \\
\hline Species group 2 & b & $\mathrm{d}$ & $\mathrm{d}$ & b & NA \\
\hline Species group 3 & $\mathrm{~b}$ & b & b & c & NA \\
\hline Species group 4 & b & b & $\mathrm{a}$ & $\mathrm{a}$ & NA \\
\hline Species group 5 & $\mathrm{~b}$ & $\mathrm{a}$ & $\mathrm{b}$ & b & NA \\
\hline
\end{tabular}

Notes: Identical letters indicate that species had an identical effect on the target. Intraspecific competion indices are indicated in italics.

on species distributions (Zimmerman et al. 1994). Some consequences of this interaction between land use history and hurricane damage are that (1) there are more gaps formed in the northern section of the LFDP, (2) pioneer and secondary species tend to preferentially colonize and be recruited into the northern part of the plot, and (3) this spatial distribution of species favors the interaction among pioneer and secondary forest species in the northern part of the plot and late-successional species in the southern part of the plot. In general, a large proportion of small stems for secondary and pioneer species were saplings that appeared immediately after Hurricane Hugo. Consequently, previous damage to adult trees of pioneer and secondary forest species holds little explanatory value for the growth of the majority of target trees of these same species.

Survival.-Previous hurricane damage affected subsequent probability of survival for all 12 of the target species. Generally, the effects of hurricane damage on subsequent survival appear to be driven primarily by the ability of target species to take advantage of competitive release resulting from damage to neighboring adults (parameter $\eta$, Table 6).

\section{Competitive coefficients}

Understanding the strength of interactions between species is essential to linking process and pattern in natural plant communities. Quantifying the magnitude and significance of these interactions is also at the heart of an important and ongoing debate in ecology, namely the importance of competition (i.e., niche differentiation) in structuring natural plant communities (Connell 1983, Welden and Slausen 1986, Hubbell 2001). Several recent studies have presented non-manipulative methods to quantify the strength of species interaction in natural communities (see review in Freckleton and Watkinson 2001). Our method offers great promise as a tool to calculate species interactions in forest communities using data from permanent census plots.

Growth.-Our results contradict the idea that all competitors have equivalent per capita effects on a target or that the effect of competitors is simply proportional to their size (Goldberg 1987). We found distinct functional groupings of competitors idiosyncratic to each target species. For a few species, the effects of conspecifics on target species growth were stronger than effects of the majority of heterospecific neighbors for about half of the target species. These results could 
TABLE 8. Extended.

\begin{tabular}{|c|c|c|c|c|c|c|}
\hline \multicolumn{7}{|c|}{ Competitive coefficients } \\
\hline GUAGUI & INGLAU & MANBID & PREMON & SCHMOR & SLOBER & TABHET \\
\hline $\begin{array}{c}0.001 \mathrm{a} \\
(0-0.002)\end{array}$ & $\mathrm{NA}$ & $\mathrm{NA}$ & $\begin{array}{c}1 \mathrm{~d} \\
(0.99-1)\end{array}$ & $\begin{array}{c}0.0001 \mathrm{~d} \\
(0-0.0002)\end{array}$ & NA & $\mathrm{NA}$ \\
\hline $\begin{array}{c}0.20 \mathrm{c} \\
(0.19-0.21)\end{array}$ & NA & NA & $\begin{array}{c}0.10 \mathrm{~b} \\
(0.09-0.21)\end{array}$ & $\begin{array}{c}0.05 \mathrm{~b} \\
(0.04-0.07)\end{array}$ & NA & NA \\
\hline a & NA & NA & $\begin{array}{l}0.001 \mathrm{a} \\
(0-0.001)\end{array}$ & $\begin{array}{c}0.33 \mathrm{a} \\
(0.32-0.36)\end{array}$ & NA & NA \\
\hline $\mathrm{a}$ & NA & NA & $\begin{array}{c}0.91 \mathrm{c} \\
(0.47-0.92)\end{array}$ & $\mathrm{b}$ & NA & NA \\
\hline $\mathrm{a}$ & $\mathrm{NA}$ & NA & $\mathrm{b}$ & d & NA & NA \\
\hline $\begin{array}{c}0.58 \\
(0.55-0.59)\end{array}$ & NA & NA & $\mathrm{d}$ & $\mathrm{a}$ & NA & NA \\
\hline a & $\mathrm{NA}$ & NA & $\mathrm{c}$ & d & NA & NA \\
\hline $\mathrm{c}$ & NA & NA & $\mathrm{a}$ & $\mathrm{b}$ & NA & NA \\
\hline $\mathrm{c}$ & NA & NA & $\begin{array}{c}0.006 \\
(0-0.007)\end{array}$ & a & NA & NA \\
\hline $\begin{array}{c}1 \mathrm{~d} \\
(0.99-1)\end{array}$ & NA & NA & b & $\begin{array}{c}0.001 \mathrm{c} \\
(0-0.002)\end{array}$ & NA & NA \\
\hline a & NA & NA & $\mathrm{a}$ & $\begin{array}{c}1 \\
(0.99-1)\end{array}$ & NA & NA \\
\hline $\mathrm{c}$ & NA & NA & $\mathrm{a}$ & $\mathrm{c}$ & NA & NA \\
\hline $\mathrm{a}$ & NA & NA & b & $\mathrm{c}$ & NA & NA \\
\hline $\mathrm{a}$ & NA & NA & a & d & NA & NA \\
\hline $\begin{array}{c}0.02 \mathrm{~b} \\
(0-0.03)\end{array}$ & $\mathrm{NA}$ & NA & d & $\mathrm{c}$ & NA & NA \\
\hline $\mathrm{a}$ & NA & NA & $\mathrm{c}$ & $\mathrm{d}$ & NA & NA \\
\hline b & NA & NA & d & c & NA & NA \\
\hline $\mathrm{c}$ & NA & NA & c & d & NA & NA \\
\hline $\mathrm{c}$ & NA & NA & b & $\mathrm{c}$ & NA & NA \\
\hline
\end{tabular}

simply be the result of greater intraspecific spatial aggregation in this group of species. To explore this possibility, we calculated spatial aggregation indices at 20 $\mathrm{m}$ scale for all target species using the method described in Condit et al. (2000). The relationship between the value of the intraspecific coefficient and aggregation was low $\left(r^{2}=0.05\right)$. Thus, predominant contacts with conspecifics are not driving the relative strength of intraspecific vs. interspecific competitive coefficients. In the absence of a strong spatial effect, our results support the idea that, for some species, similar resource requirements will act to promote species diversity through density dependent effects. These findings contradict results from previous studies that measured both intraspecific and interspecific competition (Goldberg and Barton 1992, Law et al. 1997). At this time, we cannot ascribe a biological meaning to these estimated competitive coefficients but it seems logical that they reflect a variety of neighborhood dependent, life history traits and tradeoffs (e.g., dispersal ability, shade tolerance; see Reich et al. 1999, Wright 2002) that determine the position of each species in the community.

Survival.-We found mixed support for a model that assumed functional equivalence of competitors on mortality. We detected distinct effects of different functional groups of neighbors on survival for Alchornea latifolia, Buchenavia tetraphylla, Casearia arborea,
Cecropia scheberiana, Guarea guidonia, Prestoea acuminata, and Schefflera morototoni. What factors determined our ability to detect distinct effects of competitors on target survival? A combination of causes may be required to explain our findings. (1) Pioneers suffered very high mortality as the canopy recovered

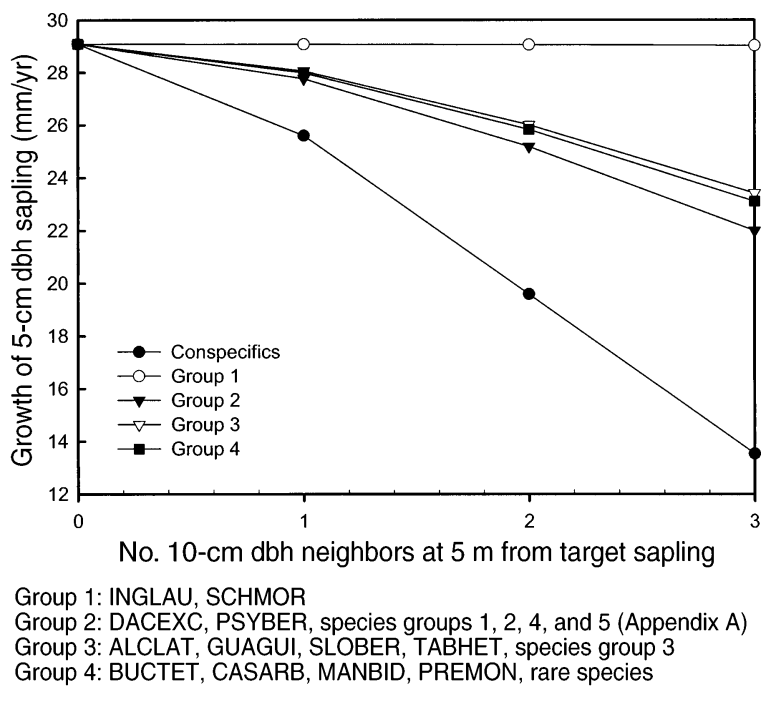

FIG. 8. Effects of different neighbor groups on the growth of a 5-cm dbh sapling of Cecropia schreberiana for the most parsimonious model. Species codes are identified in Table 1. 
from hurricane damage. One obvious interpretation is that large numbers of dead stems for these two pioneers facilitated our detection of distinct neighbor effects on survival. A similar argument applies for Prestoea acuminata, the most numerous species in the plot. For many of the remaining competing species, small sample sizes for distinct competitors in the neighborhood of dead target trees may have hindered our ability to detect distinct effects for each of the competing species. (2) Biological attributes of species also affected our ability to detect distinct neighbor effects. For instance, conspecifics had distinct effects on the survival of $\mathrm{Al}$ chornea latifolia and Casearia arborea (Fig. 6). The effect of conspecifics on survival of these two target species was stronger than that of heterospecific competitors. Both of these species are non-pioneer light demanding species that occur in spatially aggregated patterns and may compete primarily with conspecifics for light and soil resources.

Growth and mortality.-The fact that the majority of mortality occurs in small size classes whereas growth is estimated across the whole range of sizes makes it difficult to compare results for the growth and survival model. In general, growth of target species was more sensitive to the identity of neighbors than survival. Conspecific or group effects were important for the survival of pioneer and light-demanding, nonpioneer species but not for late-successional species. Low numbers of dead trees in late-successional species may have hindered our ability to detect distinct responses to the identity of neighbors in the survival of this group of species.

Our method offers a series of hypotheses about competitive hierarchies at the LFDP that can be tested using experimental approaches. For instance, we found that the effects of conspecifics on Dacryodea excelsa growth were stronger than that of heterospecifics. This is consistent with the grafting habit of D. excelsa (Basnet et al. 1993), which may increase competition for resources between neighboring conspecifics, particularly when large size asymmetries exist between grafted neighbors. Experiments can attempt to uncover the mechanisms that determine competitive interactions between species at the LFDP. Moreover, estimated parameters such as $\lambda$ values can be included as part of a suite of life history traits that allow niche partitioning among coexisting species (i.e., Freckleton and Watkinson 2001). Whether such niche partitioning results in ecological neutrality and equivalent per capita fitnesses is one interesting hypothesis that remains to be tested.

\section{Implications for modeling the dynamics of tropical forests}

A large percentage of individual variation in growth remains unexplained. We can only speculate on possible sources for the remaining variation. There are three general classes of variation that need to be considered: (1) physical measurement error (i.e., unavoid- able error in the estimation of growth from repeated measurements of tree size); (2) model specification error, or the inability of the functional forms in our equations to adequately represent competitive interactions; and (3) biological (plant-to-plant) variation in both competitive effects and responses. Of these three sources, the last class is of greatest importance for models of tropical forest dynamics. The scale of spatial autocorrelation of growth (and residuals of our model) was strongest within a 5-m radius from target trees and dropped off dramatically at greater distances suggesting that the most likely candidate for biological variability may be habitat variation (e.g., soil nutrient or water availability) over small patches. Efforts to understand the effects of soil heterogeneity at LFDP are underway and will determine whether this factor is an important driver of growth in this forest. Studies of herbaceous plants and some trees (e.g., loblolly pine in Atwood et al. 2002) also suggest that genetic makeup is likely to account for a large proportion of variation in both growth and survival. Finally, historical factors (e.g., recent release from neighborhood crowding, herbivore damage, physical damage) are likely to be additional sources of variation (Wright et al. 2000). Most current models of forest dynamics (e.g., SORTIE, Pacala et al. 1996) use deterministic functions for growth and mortality. Our results suggest that it will be important to expand the capabilities of those models to consider either stochastic models and/or deterministic models that consider multiple sources of individuallevel variability in growth and mortality as well as uncertainty in resources (Beckage and Clark 2003, Clark et al. 2003).

\section{ACKNOWLEDGMENTS}

We thank the founders of the LFDP, E. M. Everham, III, R. B. Waide, D. J. Lodge, and C. M. Taylor. J. Thomlinson helped to prepare the tree maps. N. Brokaw and R. John offered useful suggestions on the manuscript. The Luquillo field crews inventoried the plot. This work was supported by an NSF Postdoctoral Fellowship to M. U., NSF DEB-0087214 to C. D. C. and J. T., and additional funds from NSF LTER program and the Andrew W. Mellon foundation. This study is a contribution to the program of the Institute of Ecosystem Studies.

\section{Literature Cited}

Atwood, R. A., T. L. White, and D. A. Huber. 2002. Genetic parameters and gains for growth and wood properties in Florida source loblolly pine in the southeastern United States. Canadian Journal of Forest Research 32:1025-1038.

Basnet, K., F. N. Scatena, G. E. Likens, and A. E. Lugo. 1993. Ecological consequences of root grafting in tabonuco (Dacryodes excelsa) trees in the Luquillo Experimental Forest, Puerto Rico. Biotropica 25:28-35.

Beckage, B., and J. S. Clark. 2003. Seedling survival and growth of three forest tree species: the role of spatial heterogeneity. Ecology 84:1849-1861.

Bella, I. E. 1971. A new competition model for individual trees. Forest Science 17:364-372.

Blundell, A. G., and D. R. Peart. 2001. Growth strategies of a shade-tolerant tropical tree: the interactive effects of can- 
opy gaps and simulated herbivory. Journal of Ecology $\mathbf{8 9}$ 608-615.

Botkin, D. B., J. F. Janak, and J. R. Wallis. 1972. Rationale, limitations, and assumptions of a northeastern forest simulator. International Business Machines Journal of Research and Development 16:106-116.

Boucher, D. H., J. H. Vandermeer, M. A. Mallona, N. Zamora, and I. Perfecto. 1994. Resistance and resilience in a directly regenerating rainforest: Nicaraguan trees of the Vochysiaceae after Hurricane Joan. Forest Ecology and Management 68:127-136.

Buchman, R. G., S. D. Pederson, and N. R. Walters. 1983. A tree survival model with application to species of the Great Lakes region. Canadian Journal of Forest Research 13:601-608.

Canham, C. D. 1988. An index for understory light levels in and around canopy gaps. Ecology 69:1634-1638.

Canham, C. D., P. T. LePage, and K. D. Coates. 2004. A spatially-explicit analysis of canopy tree competition: effects of shading versus crowding. Canadian Journal of Forest Research. 34:778-787.

Chai, F. Y. C., and V. M. LeMay. 1993. Developing and testing of diameter increment models for mixed swamp forests of Sarawak. Forest Ecology and Management 58: 51-64.

Clark, D. A., and D. B. Clark. 1992. Life history diversity of canopy and emergent trees in a neotropical rain forest. Ecological Monographs 62:315-344.

Condit, R. 1998. Tropical forest census plots: methods and results from Barro Colorado Island, Panama and a comparison with other plots. Springer-Verlag, Berlin, Germany.

Condit, R., et al. 2000. Spatial patterns in the distribution of tropical tree species. Science 288:1414-1418.

Condit, R., S. P. Hubbell, and R. B. Foster. 1995. Mortality rates of 205 neotropical tree and shrub species and the impact of a severe drought. Ecological Monographs 65 : 419-439.

Condit, R., and J. LaFrankie. In press. Tropical forest diversity and dynamism: results from a network of large plots. University of Chicago Press, Chicago, Illinois, USA.

Connell, J. H. 1983. On the prevalence and relative importance of interspecific competition: evidence from field experiments. American Naturalist 122:691-696.

Cooper-Ellis, S., D. R. Foster, G. Carlton, and A. Lezberg. 1999. Forest response to catastrophic wind disturbance: results from an experimental hurricane. Ecology 80:26832696.

Demaris, A. 1992. Logit modeling: practical applications. Sage Publications, Newbury Park, California, USA

Ewel, J. J., and J. L. Whitmore. 1973. The ecological life zones of Puerto Rico and the United States Virgin Islands. Forest Service Research Papers ITF-18. International Institute of Tropical Forestry, Rio Piedras, Puerto Rico, USA.

Freckleton, R. P., and A. R. Watkinson. 2001. Predicting competition coefficients for plant mixtures: reciprocity, transitivity and correlation with life history traits. Ecology Letters 4:348-357.

Frelich, L. E., and P. B. Reich. 1999. Neighborhood effects, disturbance severity, and community stability in forests. Ecosystems 2:151-166.

Goffe, W. L., G. D. Ferrier, and J. Rogers. 1994. Global optimization of statistical functions with simulated annealing. Journal of Econometrics 60:65-99.

Goldberg, D. E. 1987. Neighborhood competition in an oldfield plant community. Ecology 68:1211-1223.

Goldberg, D. E., and A. M. Barton. 1992. Patterns and consequences of interspecific competition in natural communities: a review of field experiments with plants. American Naturalist 139:771-801.
Gourlet-Fleury, S., and F. Houllier. 2000. Modeling diameter increment in a lowland evergreen rain forest in French Guiana. Forest Ecology and Management 131:269-289.

Harcombe, P. A. 1987. Tree life tables. Bioscience 37:557568.

Hegyi, F. 1974. A simulation model for managing jack-pine stands. Pages 74-90 in J. Fries, editor. Growth models for tree and stand simulation. Royal College of Forestry, Stockholm, Sweden.

Hillborn, R., and M. Mangel. 1997. The ecological detective: confronting models with data. Princeton University Press, Princeton, New Jersey, USA.

Hubbell, S. P. 2001. The unified neutral theory of biodiversity and biogeography. Monographs in population biology 32 . Princeton University Press, Princeton, New Jersey, USA.

Hubbell, S. P., J. A. Ahumada, R. Condit, and R. B. Foster. 2001. Local neighborhood effects on long-term survival of individual trees in a neotropical forest. Ecological Research 16:859-875.

Kobe, R. 1999. Light gradient partitioning among tropical tree species through differential seedling mortality and growth. Ecology 80:187-201.

Law, R., T. Herben, and U. Dieckman. 1997. Non-manipulative estimates of competition coefficients in a montane grassland community. Journal of Ecology 85:505-517.

Lieberman, D., M. Lieberman, R. Peralta, and G. S. Hartshorn. 1985. Mortality patterns and stand turnover rates in a wet tropical forest in Costa Rica. Journal of Ecology 73: 915-924.

Liogier, H. A. 1985, 1988, 1994, 1995, 1997. Descriptive flora of Puerto Rico and adjacent islands. Volumes I-V. Editorial de la Universidad de Puerto Rico, Rio Piedras, Puerto Rico, USA.

Lorimer, C. G. 1983. Test of age-independent competition indices for individual trees in natural hardwood stands. Forest Ecology and Management 6:343-360.

Lorimer, C. G., and L. E. Frelich. 1984. A simulation of equilibrium diameter distributions of sugar maple (Acer saccharum). Bulletin of the Torrey Botanical Club 111: 193-199.

Mangel, M., and C. W. Clark. 1997. Dynamic modeling in behavioral ecology. Princeton University Press, Princeton, New Jersey, USA.

Monserud, R. A., and H. Sterba. 1999. Modeling individual tree mortality for Austrian forest species. Forest Ecology and Management 113:109-123.

Moravie, M. A., M. Durand, and F. Houllier. 1999. Ecological meaning and predictive ability of social status, vigor and competition indices in a tropical rain forest (India). Forest Ecology and Management 117:221-240.

Pacala, S. W., C. D. Canham, J. Saponara, J. A. Silander, Jr., R. K. Kobe, and E. Ribbens. 1996. Forest models defined by field measurements. Estimation, error analysis and dynamics. Ecological Monographs 66:1-43.

Phillips, O. L., and A. H. Gentry. 1994. Increasing turnover through time in tropical forests. Science 263:954-958.

Reich, P. B., M. B. Walters, D. S. Ellsworth, J. M. Vose, C. Gresham, J. C. Volin, and W. D. Bowman. 1999. Generality of leaf trait relationships: a test across six biomes. Ecology 80: $1955-1969$.

Shugart, H. H., and D. C. West. 1977. Development of an Appalachian deciduous forest model and its application to assessment of the impact of chestnut blight. Journal of Environmental Management 5:161-179.

Silander, S. 1979. A study of the ecological life history of Cecropia peltata, L., an early secondary successional species in the rain forest of Puerto Rico. Thesis. University of Tennessee, Institute of Ecology, Knoxville, Tennessee, USA. 
Soil Survey Staff. 1995. Order 1. Soil survey of the Luquillo long-term ecological research grid, Puerto Rico, USA. Natural Resources Conservation Service, Lincoln, Nebraska, USA.

Swaine, M. D., and T. C. Whitmore. 1988. On the definition of ecological species groups in tropical rain forests. Vegetatio 75:81-86.

Thompson, J., N. Brokaw, J. K. Zimmerman, R. B. Waide, E. M. Everham, III, D. J. Lodge, C. M. Taylor, D. GarciaMontiel, and M. Fluet. 2002. Land use history, environment, and tree composition in a tropical forest. Ecological Applications 12:1344-1363.

Tilman, D. 1988. Ecological experimentation: strengths and conceptual problems. Pages 136-157 in G. E. Likens, editor. Long-term studies in ecology. Springer-Verlag, New York, New York, USA.

Vanclay, J. K. 1991. Aggregating tree species to develop diameter increment equations for tropical rainforests. Forest Ecology and Management 42:143-168.

Vanclay, J. K. 1995. Growth models for tropical forests: a synthesis of models and methods. Forest Science 41:7-42.

Vandermeer, J. H., D. H. Boucher, I. G. de la Cerda, and I. Perfecto. 2001. Growth and development of the thinning canopy in a post-hurricane tropical rain forest in Nicaragua Forest. Ecology and Management 148:221-242.

Vandermeer, J. H., D. Boucher, I. Perfecto, and I. G. de la Cerda. 1996. A theory of disturbance and species diversity: evidence from Nicaragua after Hurricane Joan. Biotropica 28:600-613.

Vettenranta, J. 1999. Distance-dependent models for predicting the development of mixed coniferous stands in Finland. Silva Fennica 33:51-72.

Wagner, R. G., and S. R. Radosevich. 1998. Neighborhood approach for quantifying interspecific competition in coastal Oregon forests. Ecological Applications 8:779-794.

Walker, L. R. 1991. Tree damage and recovery from Hurricane Hugo in Luquillo Experimental Forest, Puerto Rico. Biotropica 23:379-385.

Walker, L. R., N. V. L. Brokaw, D. J. Lodge, and R. B. Waide, editors. 1991. Special issue. Ecosystem, plant, and animal responses to hurricanes in the Caribbean. Biotropica 23: 313-521.

Walker, L. R., W. L. Silver, M. R. Willig, and J. K. Zimmerman, editors. 1996. Special issue. Long-term responses of Caribbean ecosystems to disturbance. Biotropica 28: 414-614.

Walsh, R. P. D. 1996. Climate. Pages 159-205 in P. W. Richards, editor. The tropical rainforest: an ecological study. Second edition. Cambridge University Press, Cambridge, UK.

Welden, C. W., and W. L. Slauson. 1986. The intensity of competition versus its importance: an overlooked distinction and some implications. Quarterly Review of Biology 61:23-44.

Wimberly, M. C., and B. B. Bare. 1996. Distance-dependent and distance-independent models of Douglas-fir and western hemlock basal area growth following silvicultural treatment. Forest Ecology and Management 89:1-11.

Wright, E. F, C. D. Canham, and K. D. Coates. 2000. Effects of suppression and release on sapling growth for 11 tree species of northern, interior British Columbia. Canadian Journal of Forest Research 30:1571-1580.

Wright, S. J. 2002. Plant diversity in tropical forests: a review of mechanisms of species coexistence. Oecologia 130:114.

Wyckoff, P. H., and J. S. Clark. 2002. The relationship between growth and mortality for seven co-occurring tree species in the southern Appalachian Mountains. Journal of Ecology 90:604-615.

You, C., and W. H. Petty. 1991. Effects of Hurricane Hugo on Manilkara bidentata, a primary tree species in the Luquillo Experimental Forest in Puerto Rico. Biotropica 23: 106-113.

Zeide, B. 1993. Analysis of growth equations. Forest Science 39:594-616.

Zimmerman, J. K., E. M. Everham III, R. B. Waide, and W. H. McDowell. 1994. Responses of tree species to hurricane winds in subtropical wet forest in Puerto Rico: implications for tropical life histories. Journal of Ecology 82:911-922.

\section{APPENDIX A}

A list of species at the Luquillo Forest Dynamics Plot and ecological group assignments is available in ESA's Electronic Data Archive: Ecological Archives M074-013-A1.

\section{APPENDIX B}

A complete list of the models is available in ESA's Electronic Data Archive: Ecological Archives M074-013-A2. 